\title{
Pharmacological interventions for adolescents and adults with ADHD: stimulant and nonstimulant medications and misuse of prescription stimulants
}

This article was published in the following Dove Press journal:

Psychology Research and Behavior Management

9 September 2014

Number of times this article has been viewed

\section{Lisa L Weyandt \\ Danielle R Oster \\ Marisa E Marraccini \\ Bergljot Gyda \\ Gudmundsdottir \\ Bailey A Munro \\ Brynheld Martinez Zavras \\ Ben Kuhar}

Department of Psychology, University of Rhode Island, Kingston, RI, USA
Correspondence: Lisa L Weyandt University of Rhode Island,

414 Chafee Hall, 142 Flagg Road

Kingston, RI 0288I, USA

$\mathrm{Tel}+\mathrm{I} 4018742193$

Fax +l 40I 8472157

Email lisaweyandt@mail.uri.edu
Abstract: Attention-deficit/hyperactivity disorder (ADHD) is a neurodevelopmental disorder characterized by symptoms of inattention, hyperactivity, and impulsivity that cause functional impairment. Recent research indicates that symptoms persist into adulthood in the majority of cases, with prevalence estimates of approximately $5 \%$ in the school age population and $2.5 \%-4 \%$ in the adult population. Although students with ADHD are at greater risk for academic underachievement and psychosocial problems, increasing numbers of students with ADHD are graduating from high school and pursuing higher education. Stimulant medications are considered the first line of pharmacotherapy for individuals with ADHD, including college students. Although preliminary evidence indicates that prescription stimulants are safe and effective for college students with ADHD when used as prescribed, very few controlled studies have been conducted concerning the efficacy of prescription stimulants with college students. In addition, misuse of prescription stimulants has become a serious problem on college campuses across the US and has been recently documented in other countries as well. The purpose of the present systematic review was to investigate the efficacy of prescription stimulants for adolescents and young adults with ADHD and the nonmedical use and misuse of prescription stimulants. Results revealed that both prostimulant and stimulant medications, including lisdexamfetamine dimesylate, methylphenidate, amphetamines, and mixed-amphetamine salts, are effective at reducing ADHD symptoms in adolescents and adults with ADHD. Findings also suggest that individuals with ADHD may have higher rates of stimulant misuse than individuals without the disorder, and characteristics such as sex, race, use of illicit drugs, and academic performance are associated with misuse of stimulant medications. Results also indicate that individuals both with and without ADHD are more likely to misuse short-acting agents than long-acting agents. These findings have implications for intervention, prevention, and future research.

Keywords: ADHD symptomatology, pharmacotherapy, nonmedical stimulant use, lisdexamfetamine, methylphenidate, amphetamine

\section{Introduction}

Attention-deficit/hyperactivity disorder (ADHD) is a neurodevelopmental disorder characterized by symptoms of inattention, hyperactivity, and impulsivity that cause functional impairment. ${ }^{1}$ Previously, ADHD was believed to be primarily a disorder of childhood that would be outgrown with the onset of puberty. Recent research, however, indicates that symptoms persist into adulthood in the majority of cases, with prevalence estimates of approximately $5 \%$ in the school age population and $2.5 \%-4 \%$ in the adult population. ${ }^{1-4}$ Academic problems are prevalent among children and adolescents with ADHD and are associated with inattention and difficulty remaining seated, following directions, and completing assignments. ${ }^{5}$ In addition, children 
and adolescents with ADHD often demonstrate disruptive, defiant, and hostile behavior. ${ }^{6,7}$ Given these academic and behavioral difficulties, children and adolescents with ADHD are more likely than their non-ADHD peers to receive lower grades, fall behind academically, receive special education services, repeat grades, and drop out of high school and are less likely to pursue college. ${ }^{5,8}$ Research suggests, however, that the symptoms of ADHD are often manifested differently in adolescence compared with in childhood. For example, symptoms of hyperactivity tend to decrease in adolescence relative to childhood and instead may be manifested as symptoms of cognitive or internal restlessness..$^{9-11}$ Adolescents with ADHD, however, continue to demonstrate similar levels of impairment as younger children with ADHD, including academic underachievement and difficulties with peers and social relationships, as well as various high-risk behaviors, including reckless driving and sexual behavior and substance use. ${ }^{12}$

Despite these impairments, students with ADHD are increasingly graduating from high school and attending college. ${ }^{13}$ However, information is lacking concerning the exact prevalence of ADHD among college students, due to privacy protection for students with disabilities under the Americans with Disabilities Act of 1990 and because many college students who meet diagnostic criteria for ADHD may not have been diagnosed with the disorder. ${ }^{14,15}$ Therefore, more information is sorely needed regarding the prevalence of the disorder in the college population and its impact on student functioning. Several investigations have examined the prevalence of ADHD and the functioning of college students with ADHD symptomatology, most of which have relied on student self-report. For example, Weyandt et $\mathrm{al}^{16}$ conducted the first study assessing ADHD symptomatology among college students and found that approximately $2.5 \%-8.7 \%$ of participants reported significant ADHD symptoms, depending on the criteria employed. More recent estimates are similar to those of Weyandt et al, indicating that approximately $2 \%-10 \%$ of college students have significant ADHD symptoms and that approximately $50 \%$ of students who receive disability services do so because of ADHD. ${ }^{15,17-19}$

In terms of the academic and psychosocial functioning of college students with ADHD, Norwalk et $\mathrm{al}^{20}$ found that students with ADHD had greater difficulty with college adjustment and poorer study habits and study skills than students without the disorder. Similarly, Shaw-Zirt et $\mathrm{al}^{21}$ found that college students with ADHD, matched with non-ADHD peers on age, sex, and grade point average (GPA) (a measure of academic performance), reported poorer academic, social, and emotional adjustment than non-ADHD participants. Other studies have revealed that college students with ADHD tend to have lower GPAs, higher rates of academic probation, and poorer test-taking strategies and are less likely to graduate from college. ${ }^{2,22-24}$ Self-reported psychological distress also appears to be more common among college students with ADHD than among those without the disorder, including poorer self-esteem and increased levels of depression and anxiety. ${ }^{21,25-27}$ Collectively, these findings indicate that students with ADHD and elevated ADHD symptomatology are beset by various challenges in the college environment. To improve the outcomes of college students with ADHD, proper identification of the disorder is crucial so that effective prevention and intervention strategies may be developed and implemented.

\section{Medical and nonmedical use of prescription stimulants}

Pharmacotherapy is the primary treatment option for children, adolescents, and adults with ADHD, including college students. ${ }^{28,29}$ US Food and Drug Administration (FDA)-approved medications for ADHD include 1) stimulants such as methylphenidate (MPH) (eg, Ritalin [Novartis International AG, Basel, Switzerland], Concerta [Janssen Pharmaceuticals Inc., Titusville, NJ, USA]), dextroamphetamine (D-AMP) (eg, Adderall [Shire plc, Dublin, Ireland], Dexedrine [GlaxoSmithKline plc, London, UK]), and lisdexamfetamine dimesylate (LDX) (eg, Vyvanse [Shire Inc., Wayne, PA, USA]), a prostimulant; and 2) nonstimulants (eg, atomoxetine, [Strattera; Eli Lilly and Company, Indianapolis, IN, USA]).

Nonstimulants (eg, atomoxetine) have been demonstrated to be safe and effective for improving ADHD symptoms among children, adolescents, and adults. ${ }^{30-33}$ Nonstimulants have been found to be effective for individuals who do not respond to stimulants and have also been recommended for treating patients with ADHD who have comorbid substance use disorder (SUD). Nonstimulants, unlike stimulants, primarily affect the norepinephrine neurotransmitter system rather than the dopaminergic system and consequently have a lower potential for abuse than stimulant medications. Stimulant medications, however, remain the first line of pharmacotherapy for individuals with ADHD. ${ }^{28,29,32}$ An extensive body of literature attests that stimulant medication, when used as prescribed, is safe and efficacious for improving attention and decreasing hyperactivity and impulsivity symptoms. ${ }^{34-42}$ Although individuals with ADHD may greatly benefit from prescription stimulant medication, given their abuse potential when not taken as prescribed, prescription stimulants have been classified as schedule II medications by the FDA. A schedule II classification indicates that although 
the medication has been approved for medical use, it has a high potential for abuse, which, in turn, may lead to physiological and/or psychological dependence. ${ }^{43}$

Numerous studies have documented that the nonmedical use of prescription stimulants, defined here as the use of stimulant medication in the absence of a valid prescription and use of prescription stimulants other than as prescribed, is a growing problem on college campuses, and college students typically report that stimulant medication is easy to obtain on campus. ${ }^{44-52}$ Indeed, large numbers of students claim to have engaged in the nonmedical use of prescription stimulants, which is reflected in lifetime prevalence rates of prescription stimulant misuse ranging from $5 \%$ to nearly $34 \%$ of students. ${ }^{53,54}$ Researchers have speculated that this increase may, in part, be explained by increasing numbers of college students receiving stimulant medication treatment for ADHD who may be distributing their medication to their peers, who may, in turn, misuse it. ${ }^{44,49}$ Due to the significant health risks associated with the nonmedical use of prescription stimulants, this behavior poses a serious public health issue. ${ }^{55}$ Consequently, studies have attempted to elucidate the characteristics of prescription stimulant misuse as well as risk and protective factors associated with this behavior.

The most commonly reported and the most strongly endorsed reason for taking prescription stimulants nonmedically is to improve attention and alertness while studying, taking exams, and writing papers: ie, cognitive and academic enhancement. ${ }^{44,45,49,52,53}$ Research has also identified several risk factors for stimulant misuse, including demographic variables such as sex, ethnicity, and psychological risk factors, such as depressive symptomatology and symptoms of inattention. The identification of malleable predictors such as the academic and psychosocial functioning of students is particularly important for prevention and intervention strategies for prescription stimulant misuse. ${ }^{56-58}$

\section{Purpose of the present study}

Given the positive association between psychological factors, ADHD symptoms, and the nonmedical use of prescription stimulants, and that college students report misusing stimulants primarily to enhance their cognitive and academic functioning, it is highly plausible that, by doing so, students are trying to compensate for the struggles they encounter in the college environment. In fact, some researchers have hypothesized that college students may be using prescription stimulants nonmedically as a coping strategy to treat ADHD symptoms: ie, to "self-medicate". ${ }^{49,57}$ Although preliminary evidence indicates that prescription stimulants are safe and effective for college students with ADHD when used as prescribed, very few controlled studies have been conducted on the efficacy of prescription stimulants for college student functioning specifically. ${ }^{37}$ The question that arises, then, is whether the medical use of prescription stimulants leads to reductions in symptoms and improved academic and psychosocial outcomes. Further, is the medical use of prescription stimulants associated with increased nonmedical use of these medications? What is the scope of prescription stimulant misuse among college students? Are certain types of medications associated with greater potential for misuse than others? Answers to these questions will greatly inform both the treatment of ADHD among college students and prevention and intervention efforts aimed at reducing the nonmedical use of prescription stimulants on college campuses.

The present study attempted to answer these questions by conducting a systematic review of the literature concerning studies that investigated 1) the efficacy of prescription stimulants for adolescents and adults, including college students, with ADHD and 2) the nonmedical use and misuse of prescription stimulants.

\section{Methods \\ Search and retrieval}

A systematic literature review was conducted according to Okoli and Schabram's ${ }^{59}$ eight-step guide. Accordingly, all researchers were trained in the protocol for searching and identifying relevant articles. Although the first study to identify stimulant misuse was conducted in 2000 by Babcock and Byrne, ${ }^{46}$ a substantial number of studies addressing stimulant misuse appeared in 2002. Therefore, we attempted to identify and retrieve all empirical studies published after 2002 that examined the efficacy of stimulants and nonstimulants and stimulant misuse with adolescents and adults. The search and retrieval process included a comprehensive search of the following bibliographic databases: PsycINFO, PsycARTICLES ${ }^{\circledR}$, MEDLINE, and ScienceDirect. Keywords and eligibility criteria were established separately for each subject. In order to identify and retrieve empirical studies that examined the efficacy of stimulants among adolescents and adults, the following keywords were used: "efficacy" + "stimulants", "efficacy" + "Ritalin", "efficacy" + "Adderall", "efficacy" + "Concerta", "ADHD” + "Ritalin", "ADHD” + "Adderall”, and "ADHD” + "Concerta". Keywords used to identify research examining the efficacy of nonstimulants and prostimulants among adolescents and adults included the following: "efficacy" + "nonstimulants", "efficacy" + "Strattera", "efficacy" + "Vyvanse", and "efficacy" + "prostimulant". Finally, keywords used to identify research examining stimulant misuse among 
adolescents and adults were: "prescription stimulant" + "misuse", "prescription stimulant" + "illicit", "methylphenidate" + "misuse", "methylphenidate" + "illicit", "prescription stimulants" + "nonmedical", and "methylphenidate" + "nonmedical".

\section{Eligibility criteria}

Studies for all search subjects were selected for review based on the following criteria.

1. The study was published in English.

2. The study was published no earlier than 2002 .

3. The study included a minimum sample size of 20 subjects.

4. The study used an original dataset (meta-analyses and reviews were excluded).

5. The study was relational, experimental, or quasiexperimental.

6. The study could be conducted worldwide.

7. The sample included adolescents (ie, participants with a mean age of $\geq 12$ years) and/or adults. Note that studies including both children and adolescents were included if the mean age of participants was $\geq 12$ years. Studies that did not report the participants' mean age and included samples with a majority of participants aged $<12$ years were excluded.

8. The sample included human subjects only and included no special groups except for persons with ADHD and learning disabilities.

9. The study used only FDA-approved medication for ADHD.

10. Eligibility criteria were established specifically for research examining the efficacy of stimulants, prostimulants, and nonstimulants.

11. The sample included a control group (guanfacine studies were excluded, as well as studies examining efficacy of nicotinic agonists).

\section{Results}

The search process resulted in identifying 2,103 sources, of which 76 met eligibility criteria. Specifically, nine studies examined the efficacy of LDX, 14 explored the efficacy of $\mathrm{MPH}$, three assessed the efficacy of amphetamine (AMPH), three explored the efficacy of both MPH and AMPH in adolescents and adults, and 47 examined stimulant misuse among adolescents and adults. Although included in the initial search process, no studies examining the efficacy of nonstimulants met eligibility criteria for the present review.

\section{Efficacy of prostimulants for adolescents and adults}

As seen in Table 1, all of the included studies $(n=9)$ demonstrated a significant improvement in the measured outcomes from LDX compared with placebo. Six of the nine included studies reported effect sizes, all of which (based on Cohen's estimates of small, medium, and large) reported medium to large LDX-related effects for improvement in ADHD and related symptoms. ${ }^{35,37,60-64}$ Although the majority of studies examined LDX effects among adults, only one study examined its efficacy among a sample of adolescents. Specifically, Findling et $\mathrm{al}^{65}$ reported that at varying doses (30, 50, and $70 \mathrm{mg} /$ day), LDX was more effective at treating ADHD than placebo. Regarding adults with ADHD, improvements from LDX have been reported for quality of life, performance productivity, and executive function. ${ }^{35,64,66}$ Large effects from LDX on improved executive function were also demonstrated in college students with and without ADHD. ${ }^{37}$ Furthermore, LDX was associated with reduced ADHD symptoms compared with placebo in a sample of college students and two different samples of adults. ${ }^{37,61,62}$ Although higher doses of LDX related to greater improvement in the reduction of ADHD symptoms in two studies, in one study differences between doses were not observed. . $^{37,61,62}$ The maintenance of efficacy of LDX compared with placebo during a 2-week randomized withdrawal phase was also demonstrated to be effective in a sample of adults with ADHD. ${ }^{67}$ Finally, findings suggest that LDX may be effective for treating individuals with comorbid ADHD and depression or SUD and in reducing ADHD symptoms. ${ }^{63}$

The most common side effects reported by participants in studies investigating the efficacy of LDX included a decreased appetite, weight loss, dry mouth, insomnia, nausea, diarrhea, dizziness, headache, nasal congestion, feeling jittery, and anxiety. Mild to moderate adverse treatmentrelated effects were generally reported by $5 \%$ or fewer treatment group participants and included insomnia, tachycardia, irritability, fatigue, increased blood pressure/hypertension, upper respiratory tract infections, anxiety, decreased libido, and dyspnea. No deaths were reported in any of the studies. The results of most LDX studies led to the conclusion that the drug has a safety profile consistent with previous studies and other long-acting stimulants.

\section{Efficacy of MPH and AMPH for adolescents and adults}

Although research examining the efficacy of LDX is in its early stages, numerous studies have examined the efficacy 


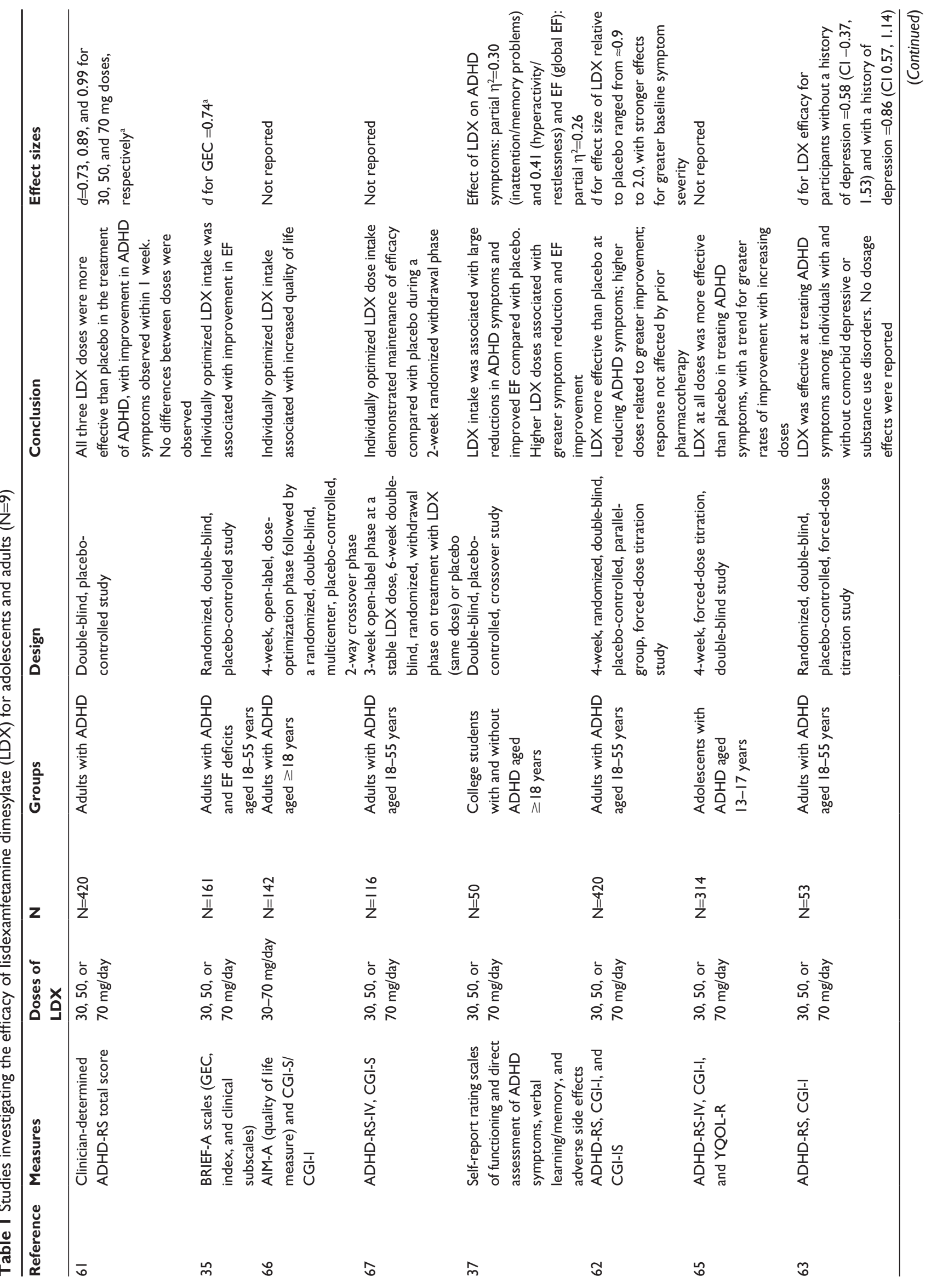


of MPH, AMPH, and mixed amphetamine salts (MAS). The included research studies examined the effects of these stimulants among samples of adolescents $(\mathrm{n}=5)$, one of which also included children, and adults ( $\mathrm{n}=15)$ (see Table 2$)$. The vast majority of studies $(n=14)$ specifically examined the effects of some form of MPH, whereas three studies examined MAS, and the remaining studies ( $\mathrm{n}=3$ ) examined a combination of MPH and MAS or AMPH. Regardless of the medication examined, all of the included studies reported statistically significant positive effects for stimulant medication compared with placebo, and effect sizes ranging from small to large based on Cohen's estimates of effect size ${ }^{60} \mathrm{~A}$ total of 14 out of 20 included studies reported effect sizes. Of the studies reporting effect sizes for positive effects from stimulant medication, most effect sizes ranged from medium to large, with two studies reporting small to medium effects. ${ }^{40,68-77}$ One study reported effect sizes regarding the interaction effects of differences between sex and medication dose, with no significant interactions found. Effect sizes ranged from very small (partial $\eta 2$ as low as 0.00 ) to small. ${ }^{78}$

Studies assessing the effects of MPH, dextroamphetamine extended release (d-MPH-ER), MPH long-acting or extended release (MPH-ER), multilayer-release MPH, and MAS, including triple-bead MAS and MAS extended release (MAS-ER), have demonstrated reductions in ADHD symptoms among adult samples. ${ }^{34,40,69-72,74-76,79-82}$ For example, Biederman et $\mathrm{al}^{83}$ reported that adults with ADHD taking osmotic release oral system (OROS)-MPH, compared with those taking a placebo, demonstrated reduced symptoms of inattention and hyperactivity/impulsivity specifically. Adolescents taking MAS-ER and MPH-ER have also been shown to demonstrate reduced ADHD symptoms. ${ }^{73,84}$

Regarding the effective dose for improvements in ADHD symptoms, doses of MPH-ER of 36-108 mg/day and $40-80 \mathrm{mg}$ /day have been shown to be effective..$^{34,40}$ Similarly, two studies reported that higher doses of MPH-ER and d-MPH-ER were more effective than lower doses at reducing ADHD symptoms among adults with ADHD..$^{70,74}$ Among adolescents, higher doses, compared with lower doses, of d-MPH-ER and MAS-ER have also been shown to relate to improvement of ADHD symptoms. ${ }^{75}$ Rösler et al, ${ }^{76}$ however, reported that even at low to moderate doses (10-60 mg/day), MPH-ER was effective at reducing ADHD symptoms and that these effects were sustained during a 24-week follow-up.

In addition to ADHD symptoms, studies have shown that MPH and MPH-ER may improve cognition and emotional symptoms, and triple-bead MAS may enhance executive 


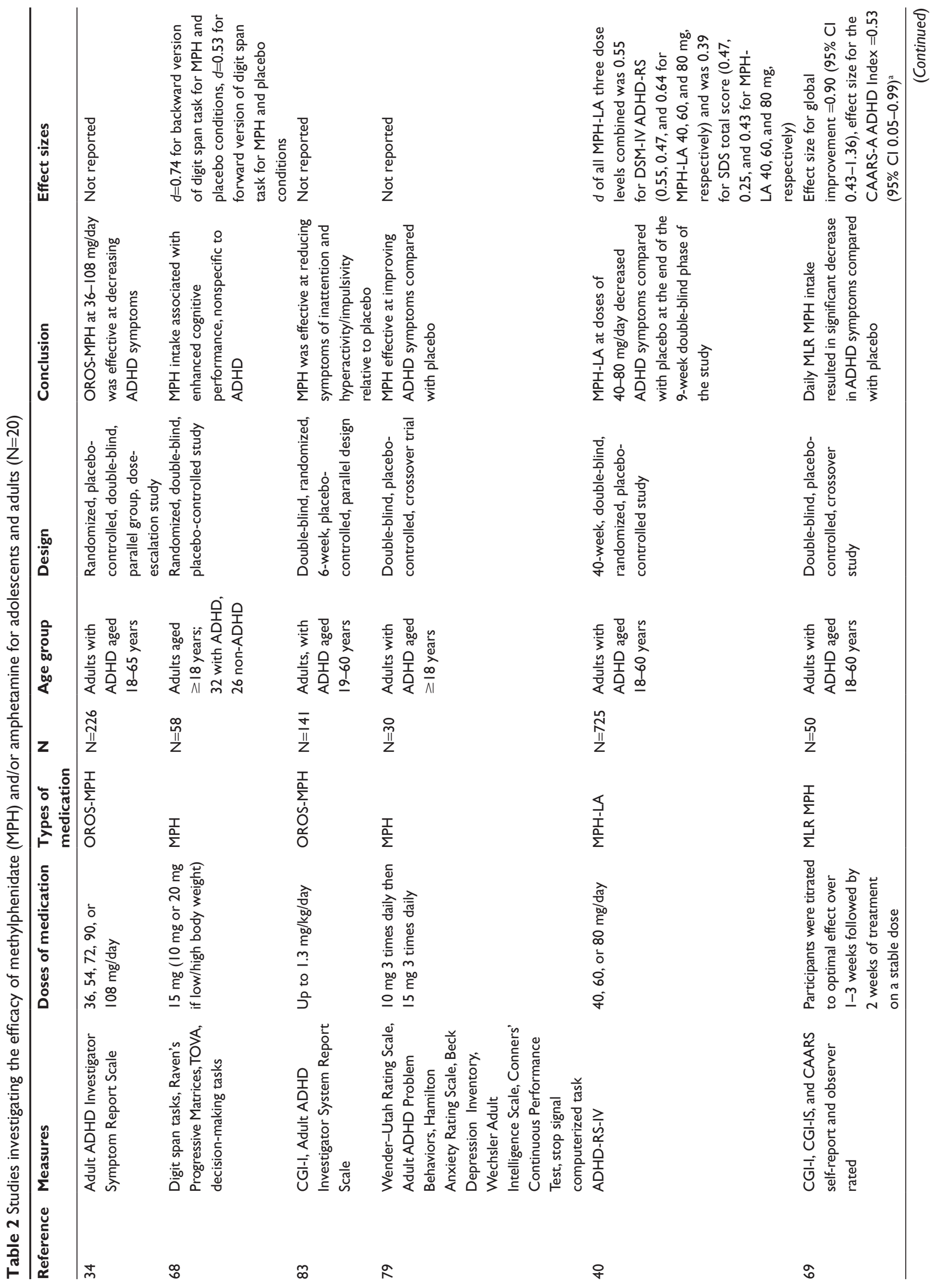




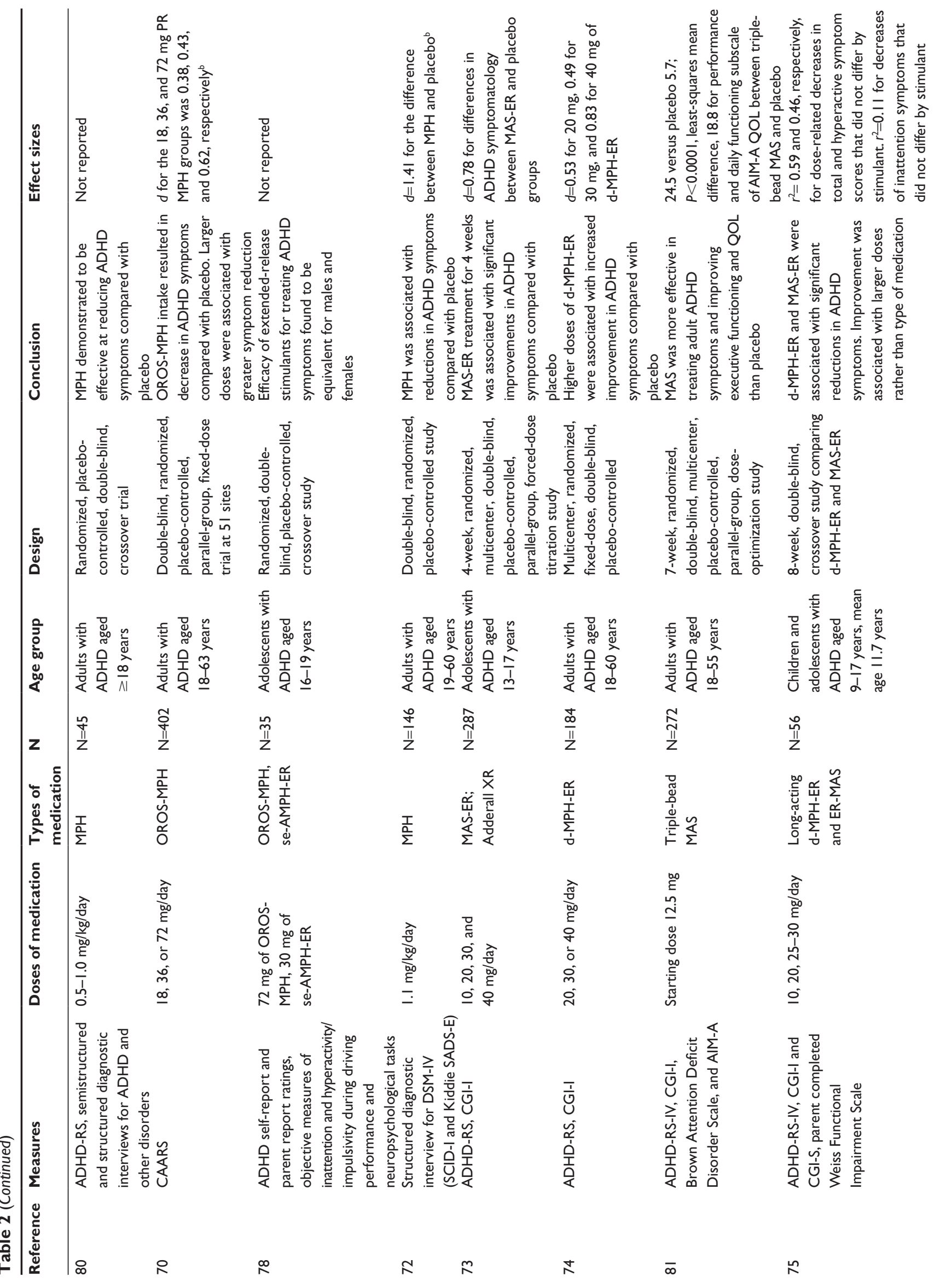



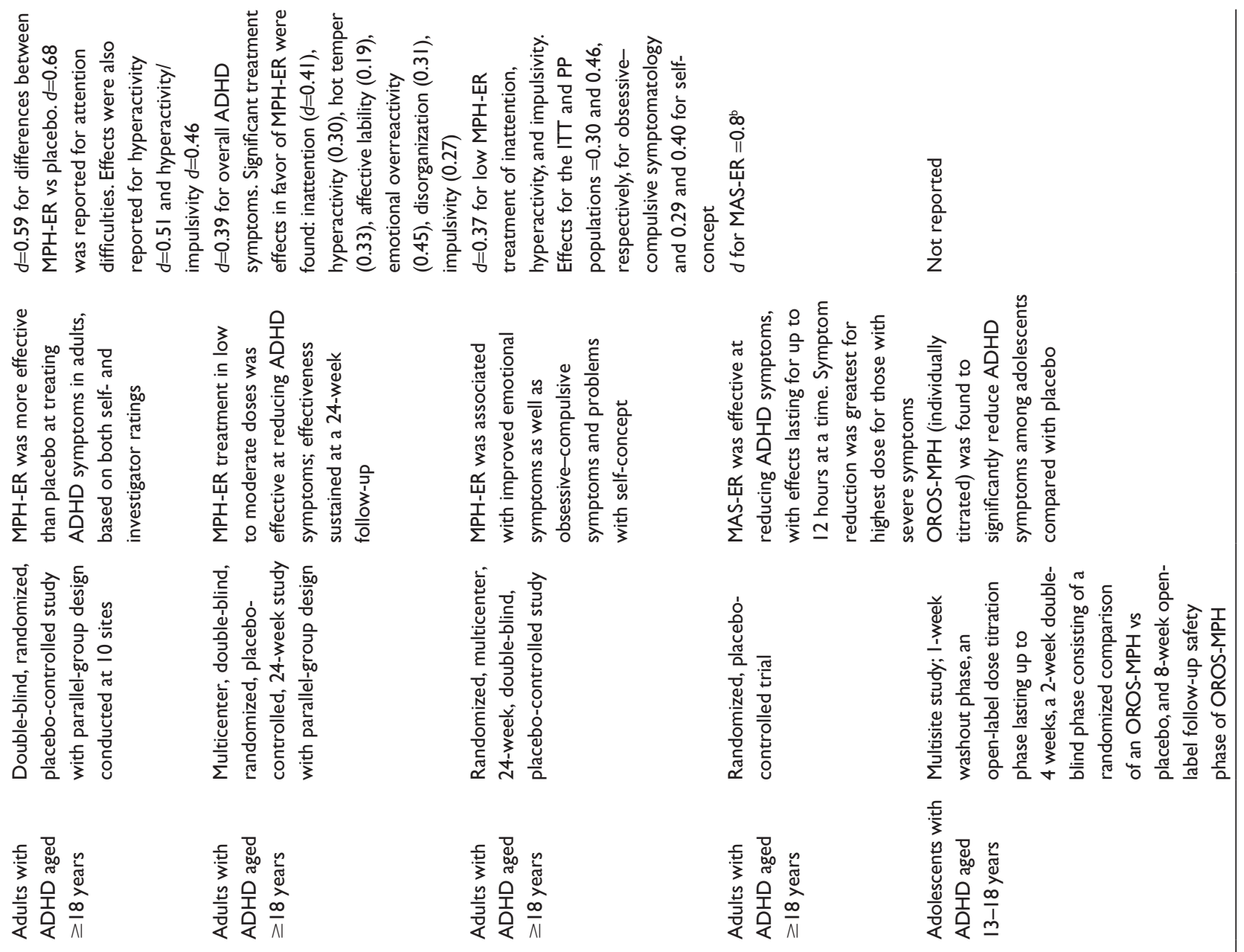

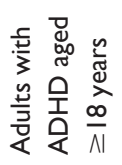
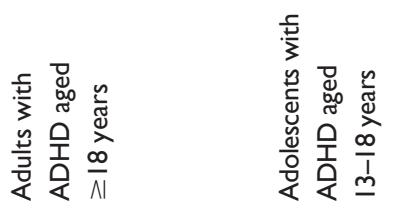

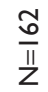

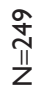

$\stackrel{m}{\stackrel{m}{Z}}$

夏

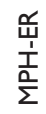

$\underset{\substack{\breve{u} \\ \frac{1}{I}}}{\frac{1}{\Sigma}}$

咭

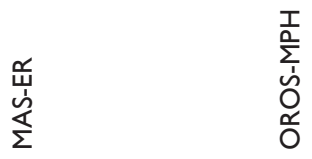

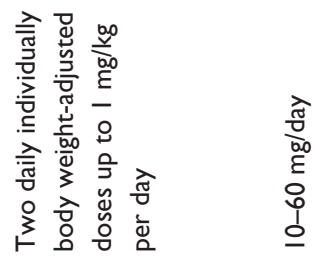

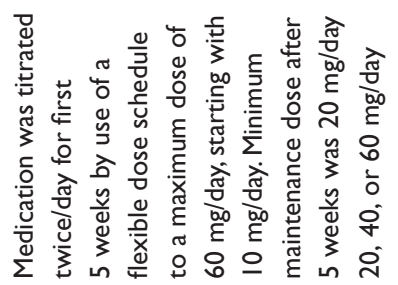

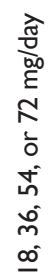

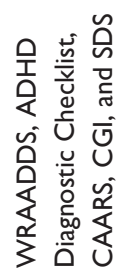

$\frac{0}{3}$

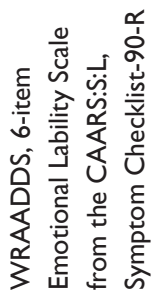

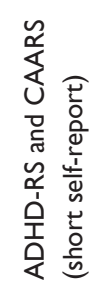

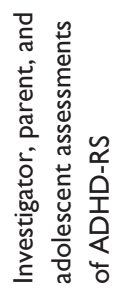

$\Sigma$

$\stackrel{2}{12}$

R

๙

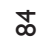




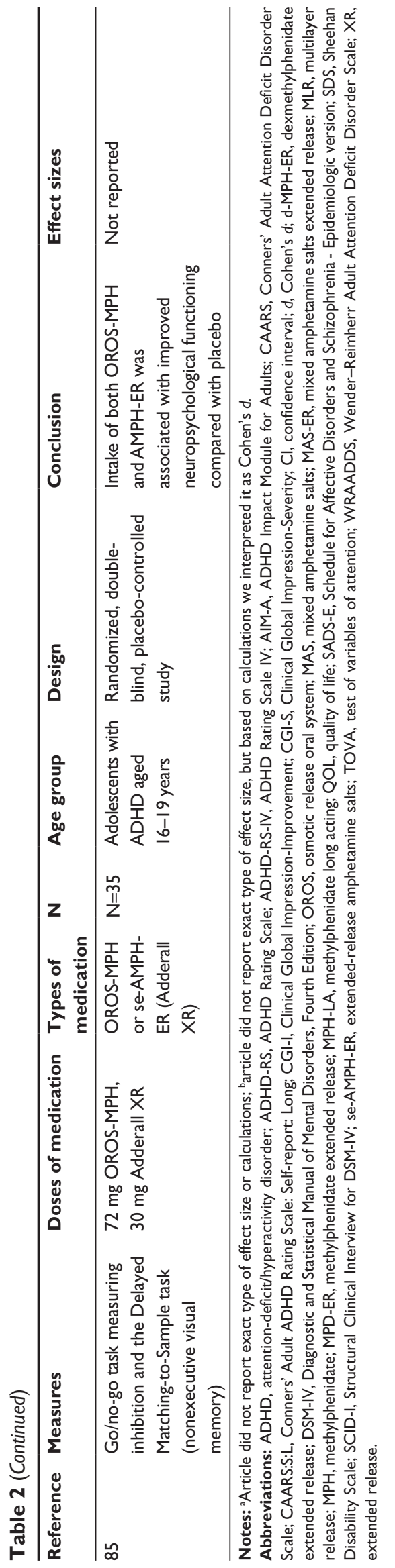

functions and quality of life among adults. ${ }^{68,77,81}$ For example, Rösler et $\mathrm{al}^{77}$ reported on a multicenter 24-week study and found that among a sample of adults with ADHD, taking MPH-ER was associated with improvement in emotional symptoms, obsessive-compulsive symptoms, and problems with self-concept. Among adolescents, one study reported that within a sample of 35 adolescents, those taking either OROS-MPH or amphetamine extended release (AMPH-ER) (Adderall XR) demonstrated improved neuropsychological functioning compared with those taking placebo. ${ }^{85}$ Finally, MPH-ER and AMPH-ER have been demonstrated to be equally effective at improving symptoms among male and female adolescents with ADHD. ${ }^{78}$

Regarding side effects in studies investigating the efficacy of D-AMP and MPH, participants most commonly reported decreased appetite, weight loss, headache, insomnia, abdominal pain, dizziness, nervousness, emotional lability, and dry mouth. Approximately half of the studies $(n=12)$ found that a majority of participants reported at least one side effect; however, mild to moderate adverse treatment-related effects were generally reported by $\leq 5 \%$ treatment group participants and included decreased weight, insomnia, tachycardia, palpitation, irritability, fatigue, increased blood pressure/ hypertension, and anxiety. No deaths were reported in any of the studies. The results of most stimulant studies led to the conclusion that the drug has a safety profile consistent with previous research. ${ }^{86}$

\section{Stimulant misuse among adolescents and adults}

The efficacy of prescription stimulants among adolescents and adults with ADHD has been well documented, but the effects of these medications among populations without ADHD are unclear. Despite a lack of empirical evidence of stimulant effectiveness in individuals without ADHD, numerous studies have documented the misuse of prescription stimulants among college students without the disorder. Indeed, the present review retrieved more research studies pertaining to stimulant misuse $(n=47)$ than the combined number of included studies assessing the efficacy of LDX, MPH, AMP, and MAS combined (see Table 3 ). The primary foci of the retrieved studies examining stimulant misuse varied. For example, some studies reported on prevalence rate estimates, others examined characteristics of individuals most susceptible to stimulant misuse, and others reported primarily on student opinions, such as ethical implications of stimulant misuse. Most of the studies, however, reported on some combination of these factors. Therefore, a systematic 


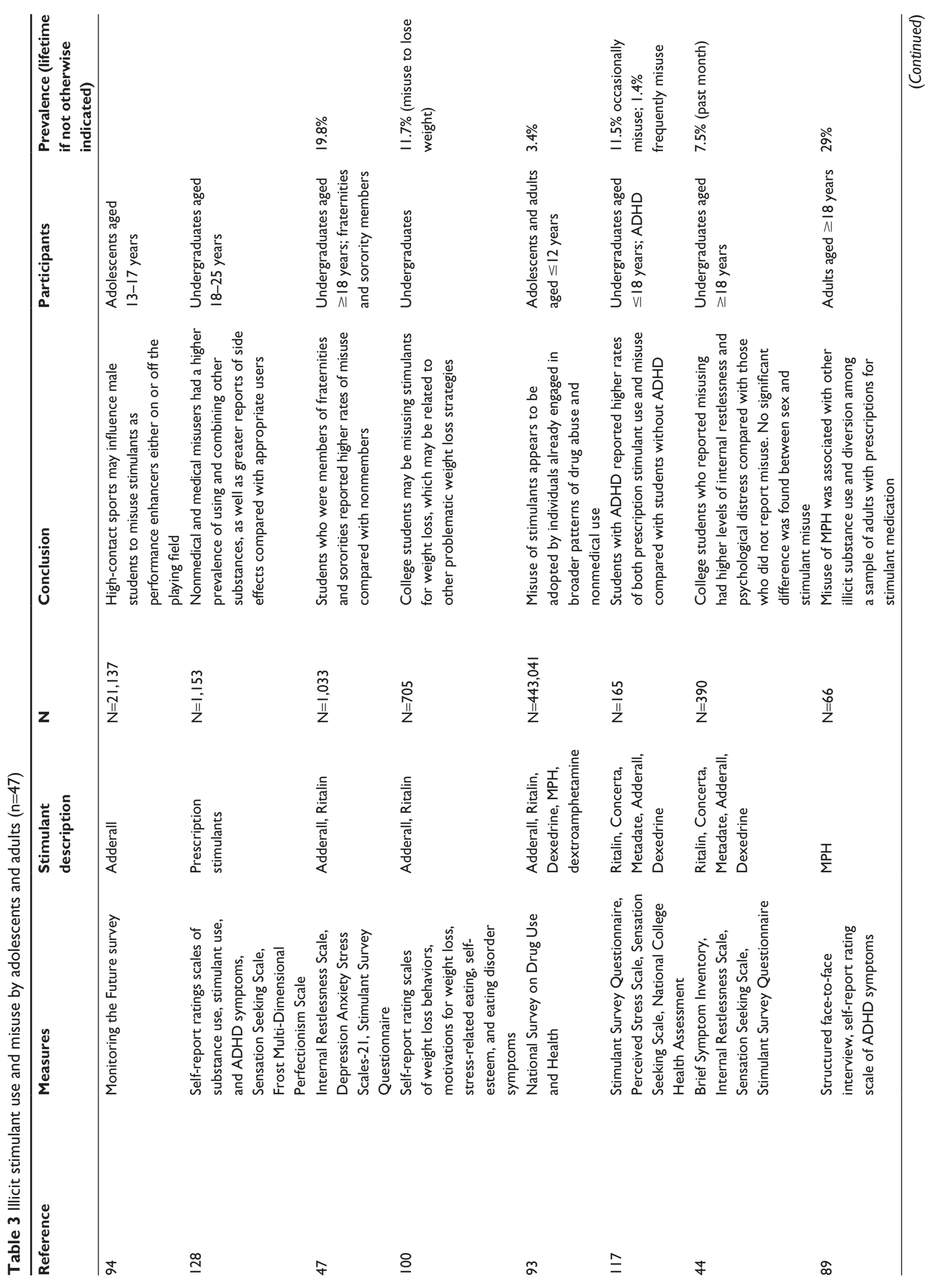




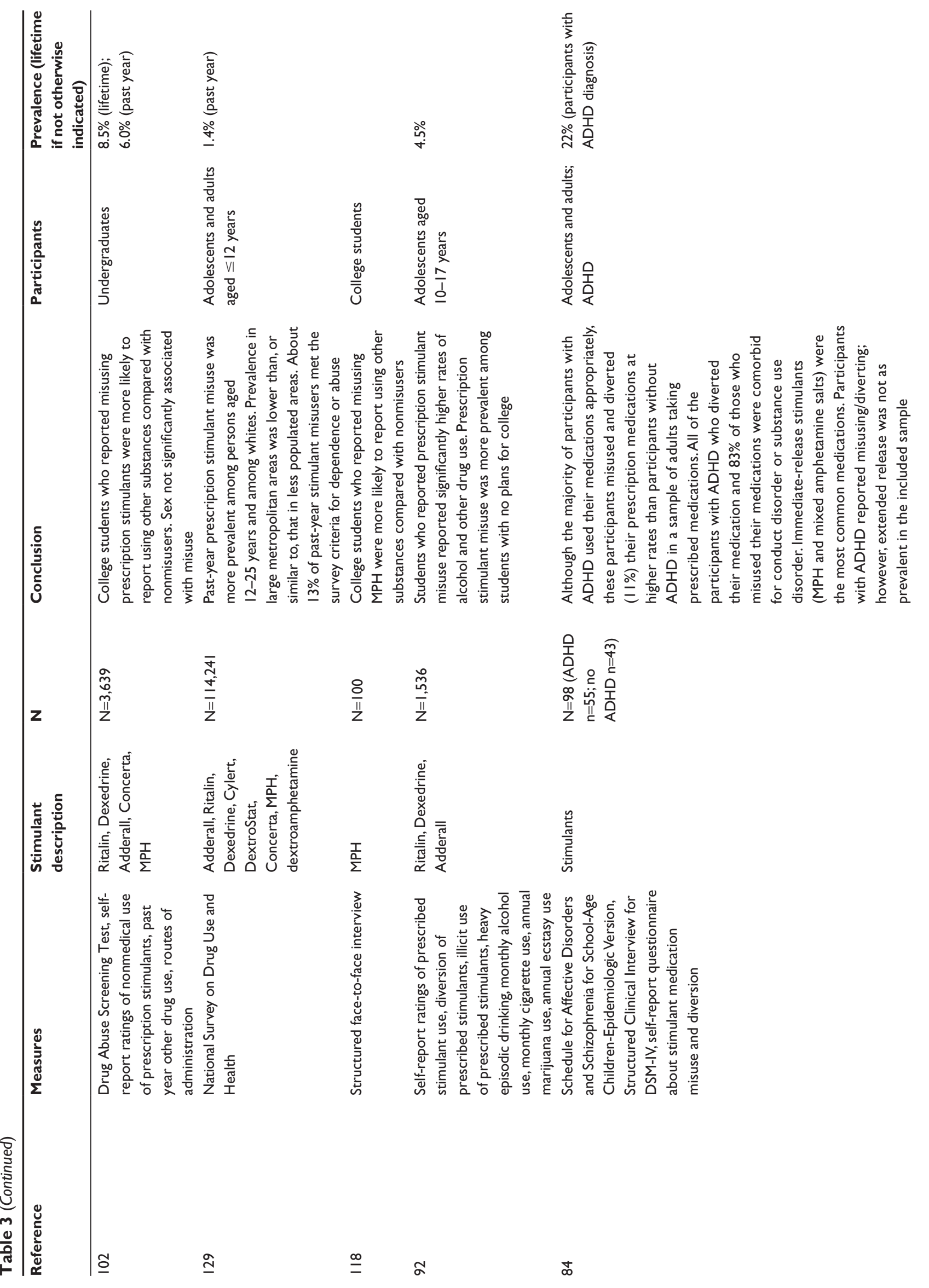


$\stackrel{\stackrel{\circ}{+}}{\stackrel{+}{+}}$

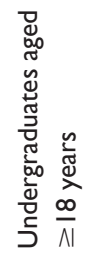

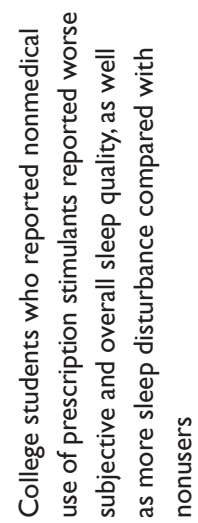

$\stackrel{\stackrel{一}{=}}{=}$

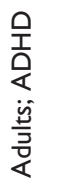

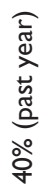

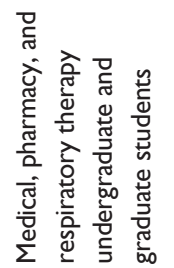

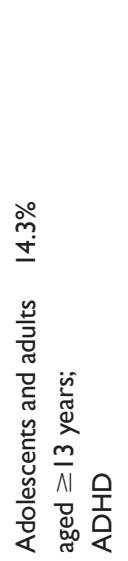
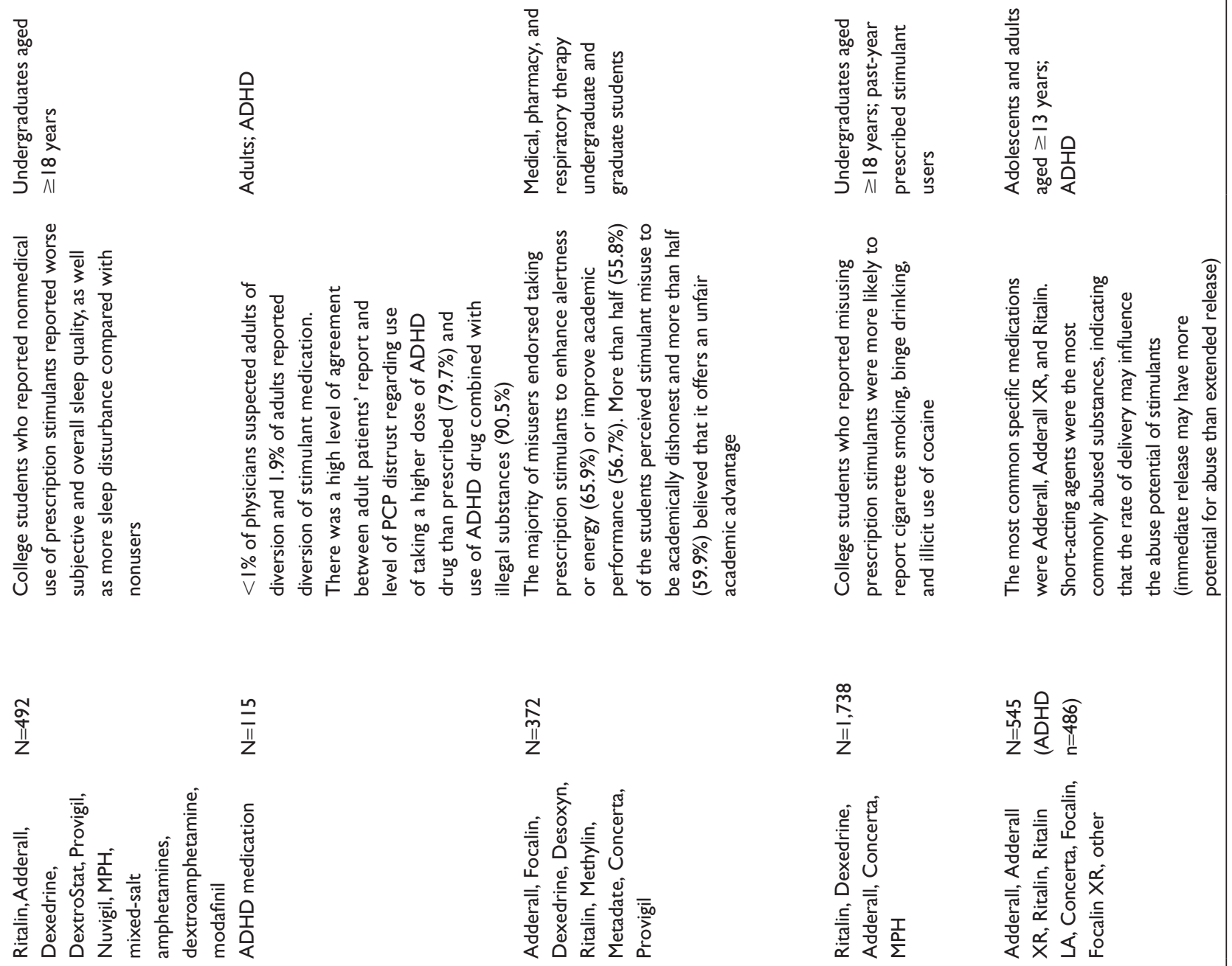

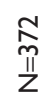
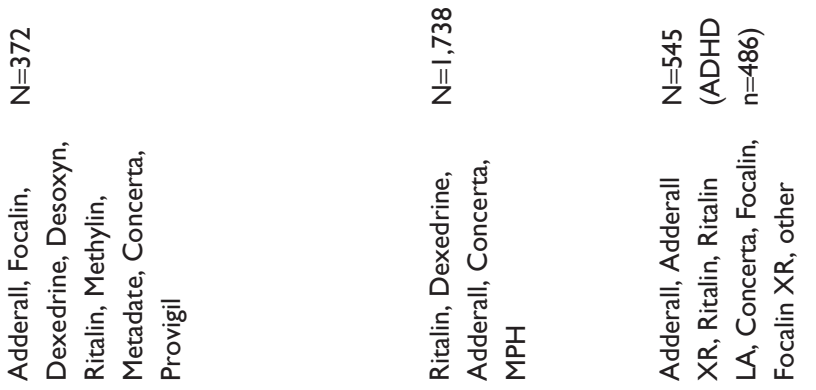

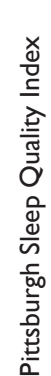
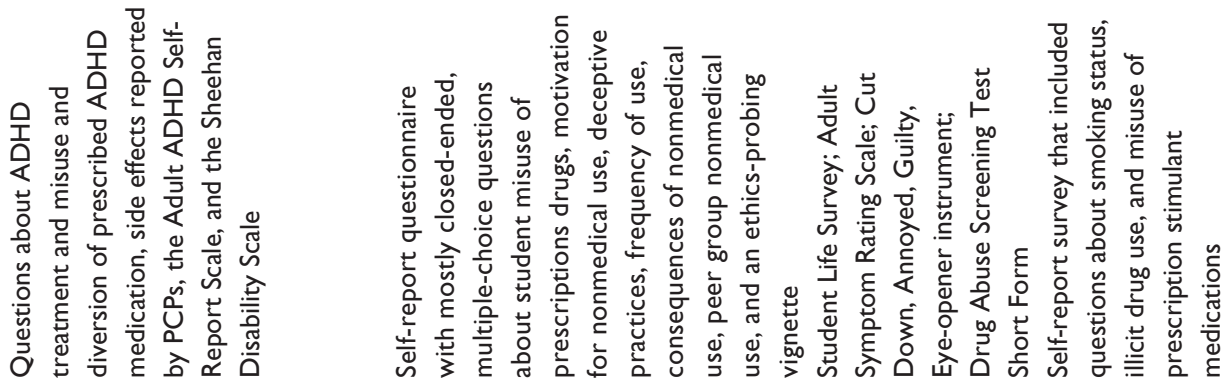

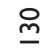

$\Xi$

$\stackrel{\infty}{\stackrel{0}{2}}$

$\stackrel{9}{=}$

๙ 


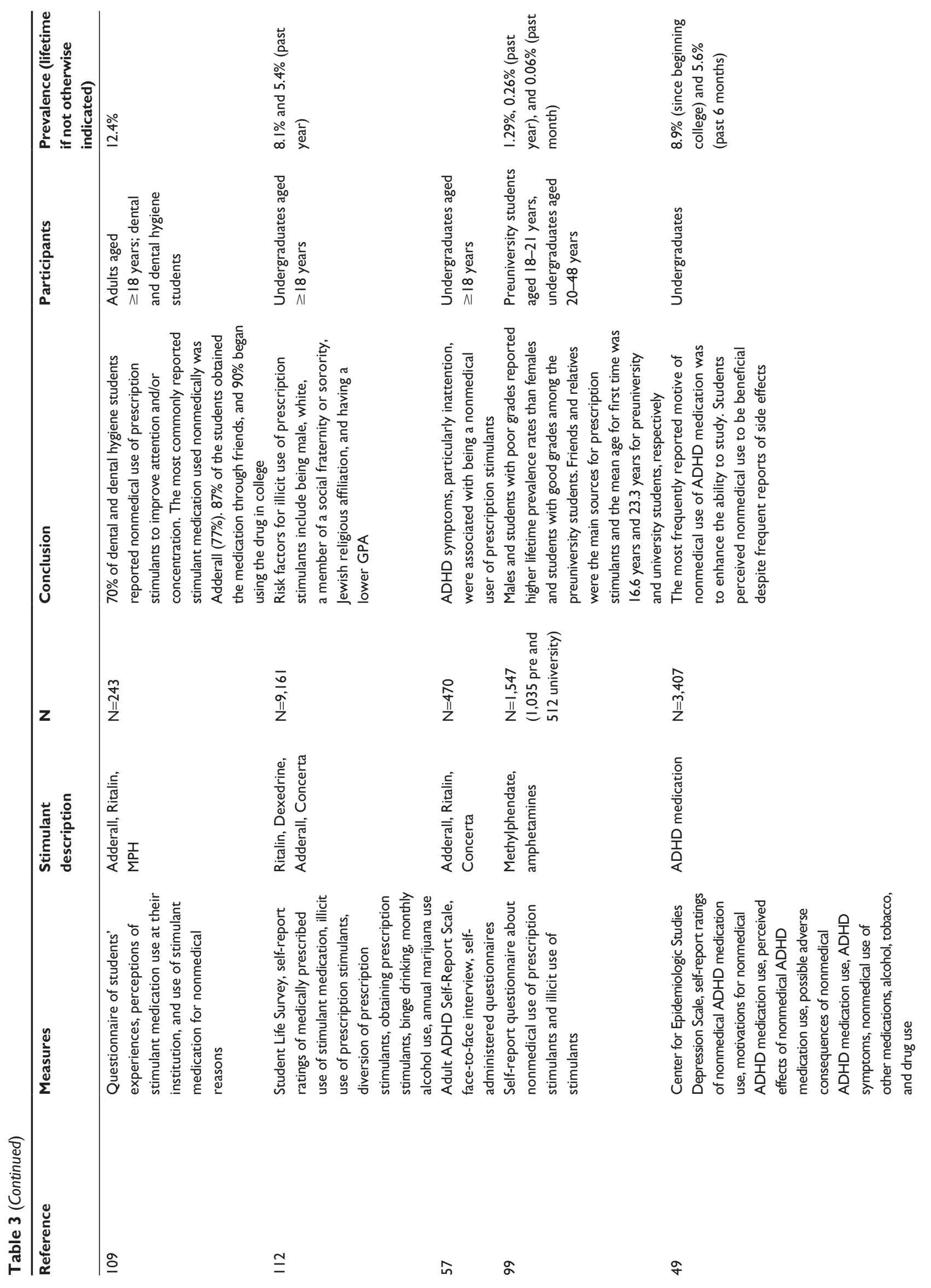




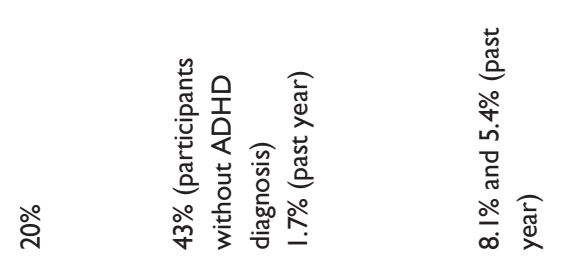

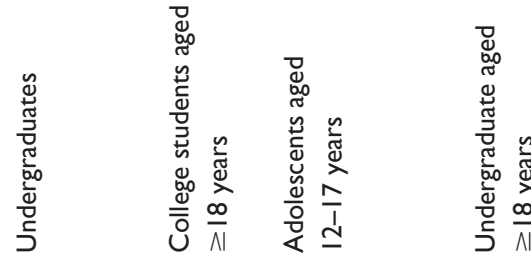

ஓें
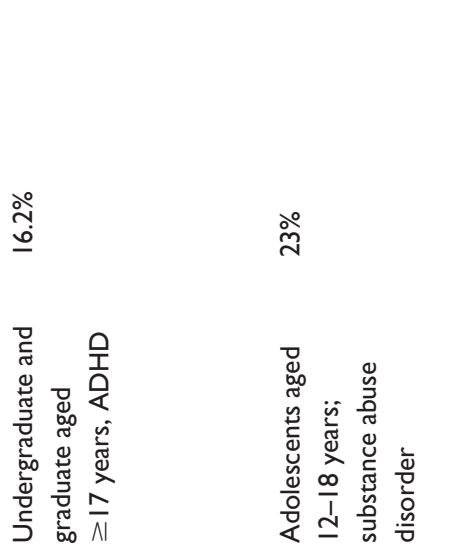

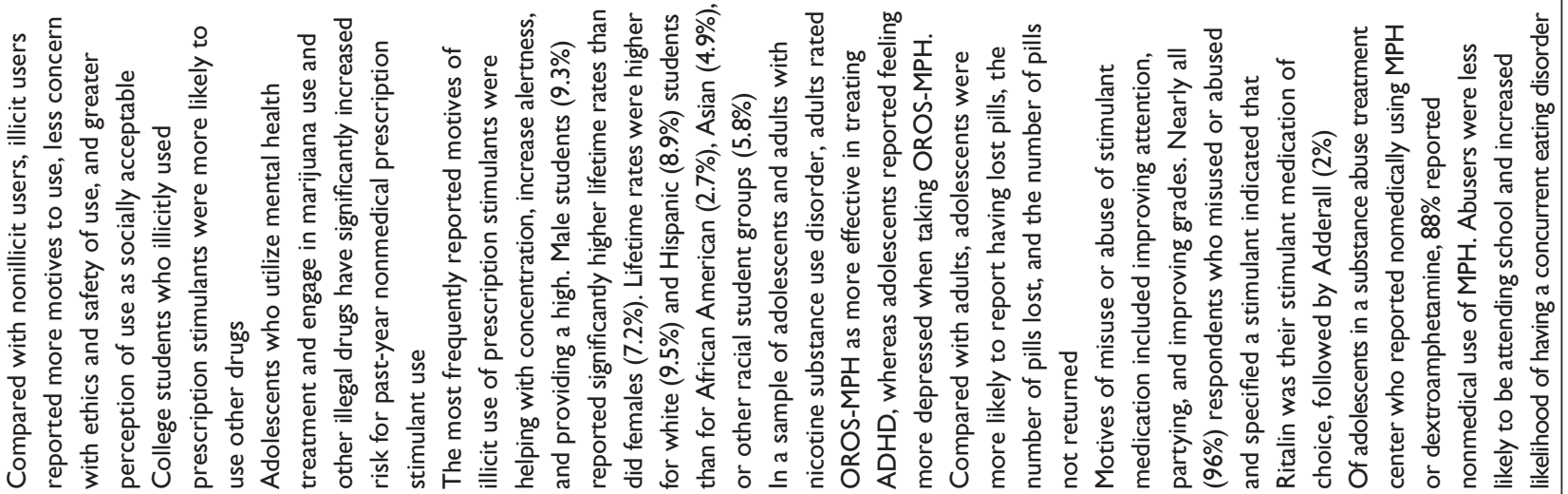

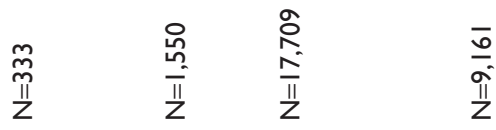

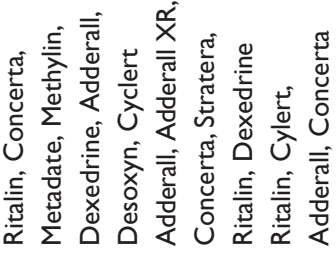

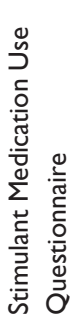

叧

$\underline{m} \quad \bar{a}$

$\stackrel{m}{=}$
望

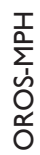

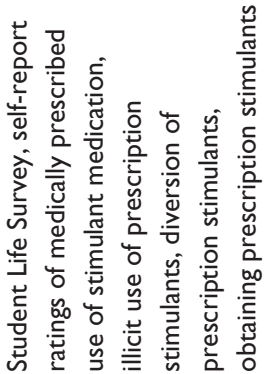

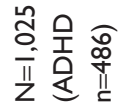
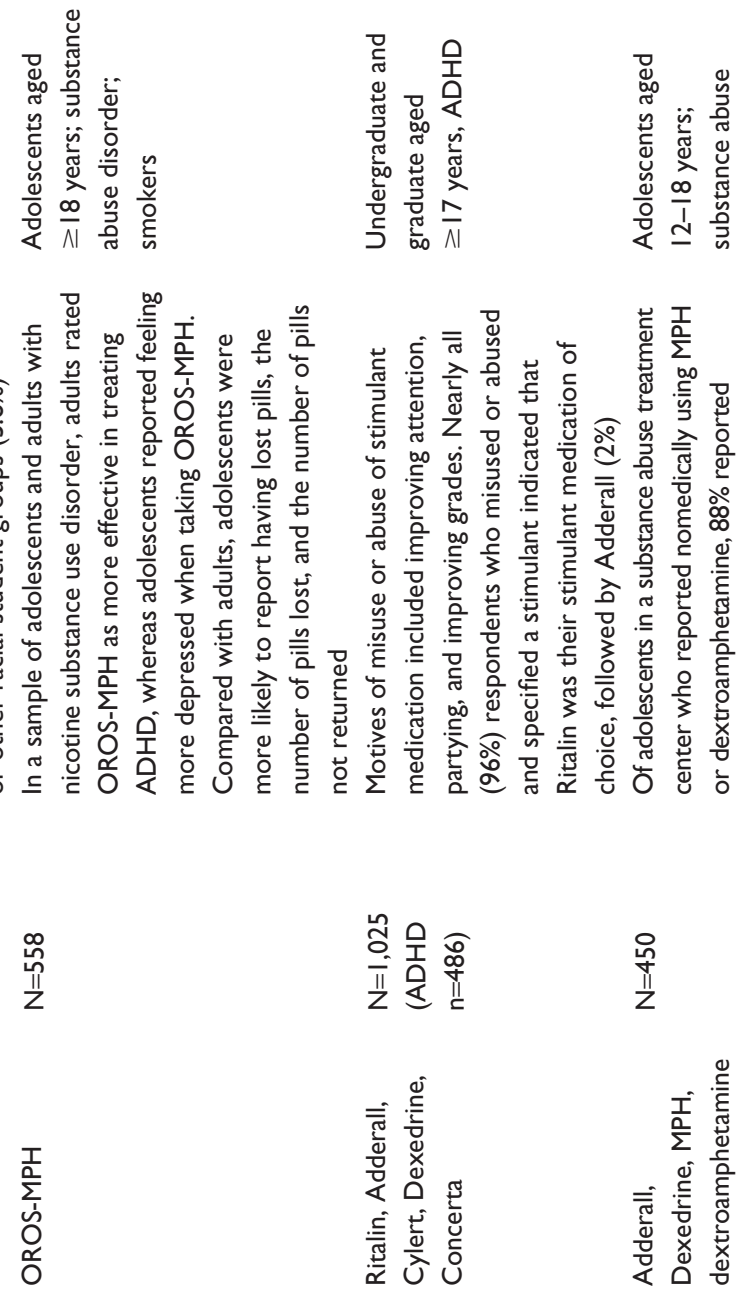

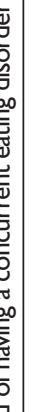




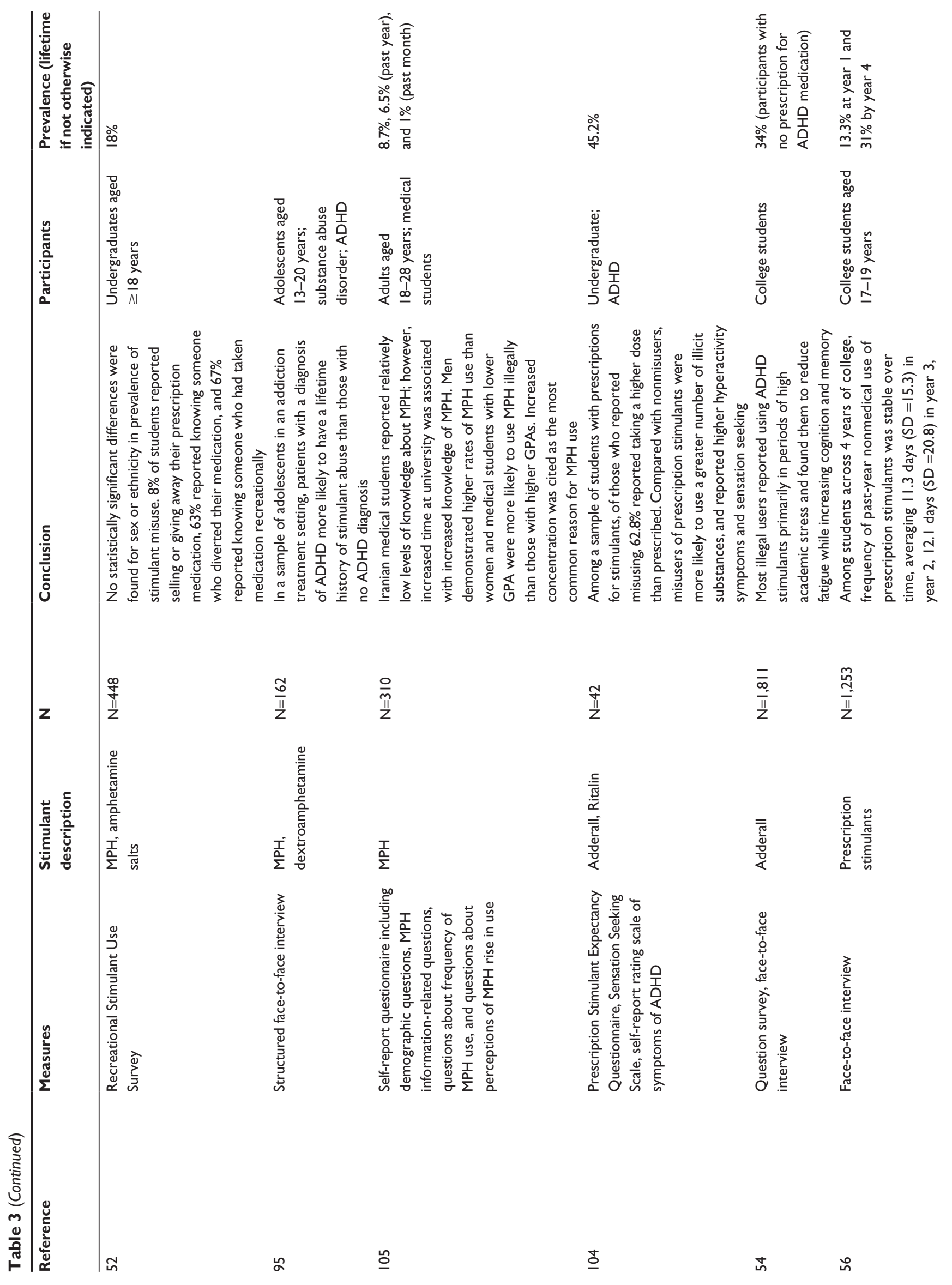



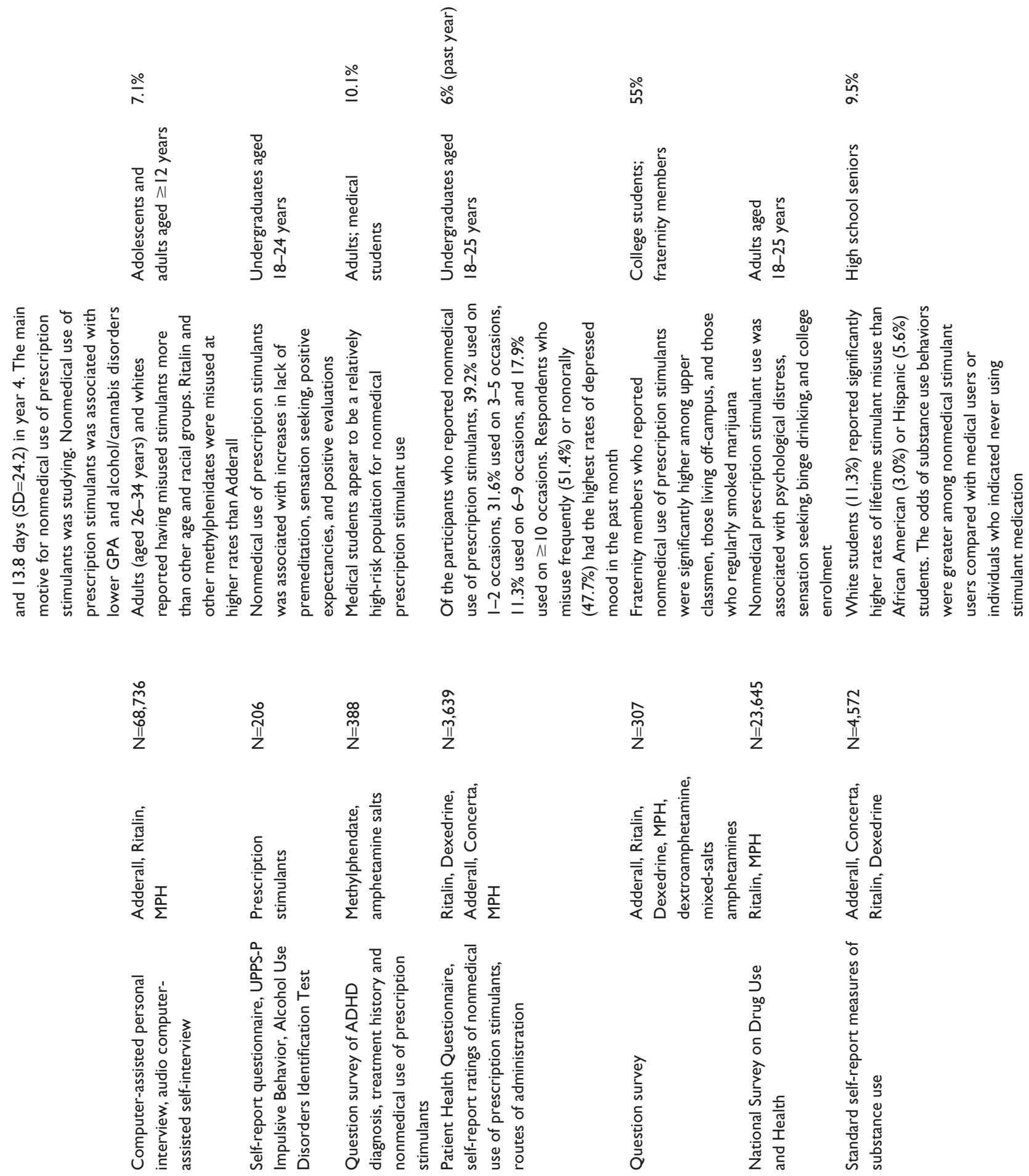

$\infty$

$\stackrel{ }{=} \quad$ 음

$\infty$

ㅇ

$\stackrel{ \pm}{=}$ 曲 


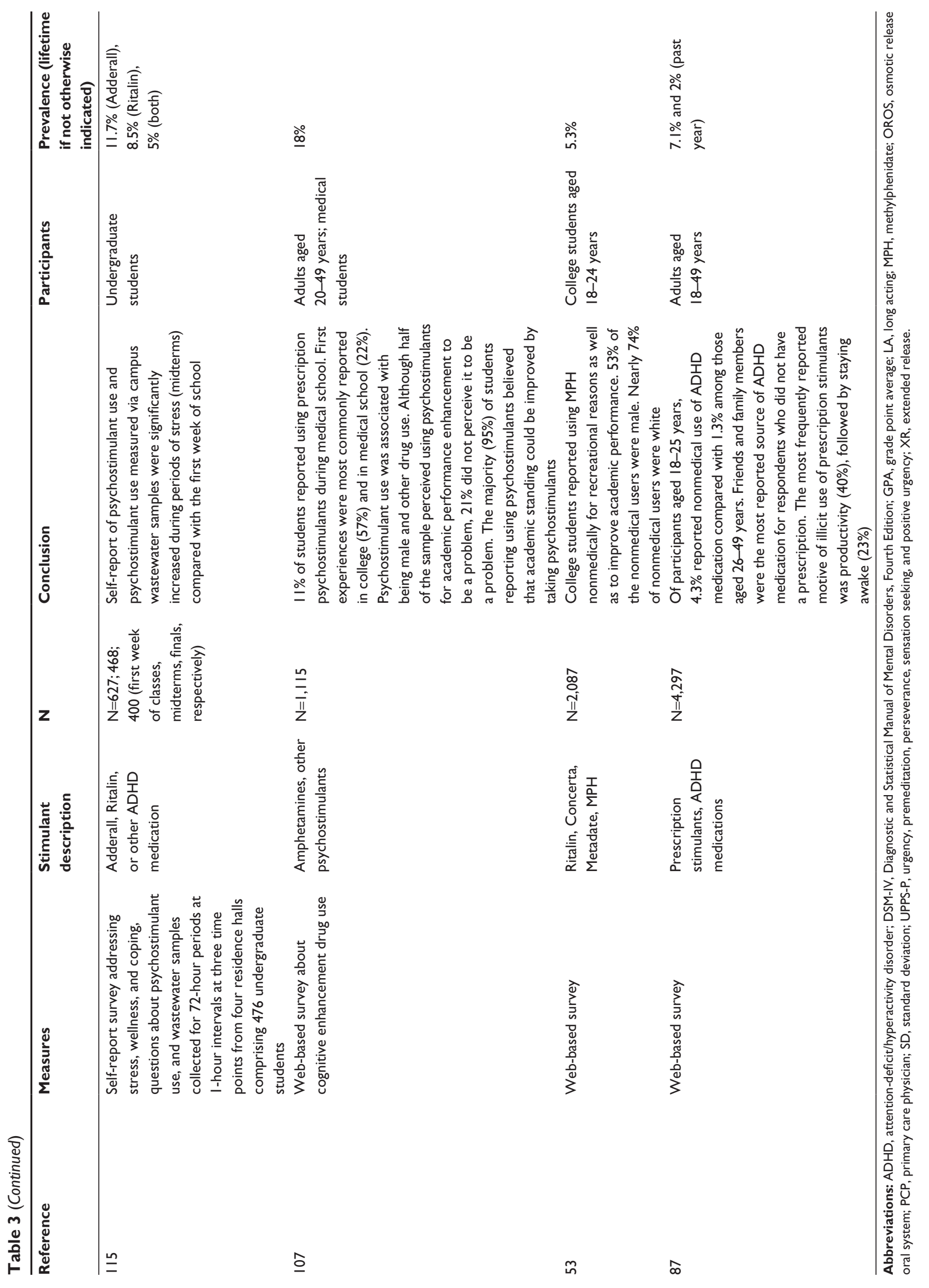


assessment and inclusion of effect sizes was beyond the scope of the present article.

The studies reviewed indicate that prescription stimulant misuse is a growing problem across adolescent and adult populations. Estimates of lifetime prevalence range from $7.1 \%$ to $29 \%$ among adults, $5.3 \%$ to $55 \%$ among college students, and $1.7 \%$ to $4.5 \%$ among adolescents. ${ }^{53,87-92}$ Although estimates of stimulant misuse prevalence appear to be relatively low among general adolescent samples, estimates of stimulant misuse among adolescents using other substances (23\%-31\%) and among adolescents and adults receiving treatment for ADHD (14\%) are much higher. ${ }^{91-97}$ Estimates of lifetime stimulant misuse also appear to increase as adolescents reach higher grade levels. For example, among high school seniors, McCabe and $\mathrm{West}^{98}$ reported that nearly $10 \%$ admitted to using prescription stimulants nonmedically at least once. Similarly, lifetime prevalence estimates in college have been shown to grow as students reach their final years of school. Garnier-Dykstra et $\mathrm{al}^{56}$ reported that although only $13.3 \%$ of first year students reported stimulant misuse, by their fourth year $31 \%$ reported misuse.

In addition to college level, lifetime estimates of stimulant misuse may vary according to several other variables. For example, prevalence of stimulant misuse specifically for cognitive enhancement was estimated to be $<2 \%$ in a sample of preuniversity (students preparing to attend university) and university students in Germany, but prevalence estimates of stimulant misuse for the purpose of weight loss has been reported to be nearly $12 \% .{ }^{99,100}$ Studies assessing stimulant misuse among general samples of college students have reported rates between approximately $8 \%$ and $34 \%{ }^{54,101,102}$ Much higher estimates of stimulant misuse have been reported among samples of college students with ADHD (43\%) or with prescriptions for stimulant medication $(45.2 \%)$. The highest estimates of prevalence of stimulant misuse among college students (55\%), however, have been reported among a sample of fraternity members. ${ }^{90,103,104}$

Among medical students, lifetime prevalence estimates for engaging in prescription stimulant misuse have ranged between $9 \%-10 \%$ and $18 \%{ }^{105-107}$ Moderate lifetime prevalence estimates of stimulant misuse have also been reported among undergraduate and graduate health care students (11\%), dental and dental hygiene students (12.4\%), and general samples including both undergraduate and graduate students $(16.2 \%-17.5 \%) .{ }^{50,108-110}$

Compared with adolescents and college students, very few studies have addressed prevalence estimates of stimulant misuse among adults aged $\geq 18$ years outside of the university setting. Novak et $\mathrm{al}^{87}$ reported that $2 \%$ of the 4,297 adults sampled indicated that they had engaged in nonmedical use of ADHD medications in the past year and $7.1 \%$ in their lifetime. Pilkinton and Cannatella ${ }^{88}$ reported similar rates $(7.1 \%)$ for lifetime prevalence estimates among a sample of both adolescents and adults. However, estimates of stimulant misuse prevalence among adults with prescriptions for stimulant medications have yielded much higher rates $(29 \%)$, similar to adolescent populations. ${ }^{89}$ Finally, Lensing et $\mathrm{al}^{111}$ explored physician and adult patient agreement regarding prescription stimulant misuse and diversion and found that $<1 \%$ of physicians suspected their patients of diversion and $<2 \%$ of the adults themselves reported diversion of prescription stimulants, yielding a high level of agreement between the two.

Studies examining characteristics of students engaging in stimulant misuse have yielded relatively consistent findings regarding sex and race/ethnicity. Although multiple studies reported that male students have indicated higher rates of lifetime stimulant misuse than female students in university settings, several studies have also failed to find differences between males and females among college students and high school senior students. ${ }^{44,52,98,99,101,105,107,110,112}$ These conflicting findings may be due to differences in measurement. For example, although Franke et $\mathrm{a}^{99}$ reported sex differences in lifetime prevalence of stimulant misuse for cognitive enhancement, the researchers did not find differences across males and females in past year or past month stimulant misuse. On the other hand, the vast majority of studies examining racial and ethnic differences related to stimulant misuse have reported that young adults, college students, and adults who are white are more likely to misuse stimulants than students

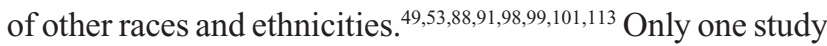
reported that there were no differences in ethnicity regarding prevalence of stimulant misuse; however, $<12 \%(n=37)$ of the study's sample included students of color, limiting statistical power and thus conclusions regarding differences in prevalence among ethnic differences. ${ }^{52}$

Interestingly, studies examining characteristics of adolescents who partake in nonmedical stimulant use indicate that students without plans to attend college have been shown to report a higher prevalence of stimulant misuse than those who plan to attend college, and adolescents who report prescription stimulant misuse may be less likely to attend school. ${ }^{94,96}$ However, college students appear to be particularly vulnerable to stimulant misuse, and members of fraternities and sororities have reported higher rates of misuse than students unaffiliated with Greek organizations. ${ }^{47,101,114}$ 
One of the reviewed studies found that college students who are upper classmen or live off-campus may be more likely to engage in nonmedical stimulant use. ${ }^{90}$ Additional correlates of stimulant misuse among college students have included affiliation with a Jewish religion, perceiving stimulant use as normative, and engaging in problematic weight loss strategies. ${ }^{100,101,115}$ Weight loss, however, may not be unique to college students, as adolescent prescription stimulant misusers have been found to be more likely to have an eating disorder than students who did not misuse stimulants. ${ }^{96}$ Finally, all types of students (adolescents, adults, and medical) performing worse academically appear to be more likely to engage in nonmedical prescription stimulant use. ${ }^{56,99,101,105}$ Indeed, this review found that the most commonly reported reasons university students take prescription stimulants are related to academics, and studies suggest that during periods of high academic stress, college students may be more likely to use prescription stimulants, as indicated by self-report measures and by measurements of stimulant levels in campus wastewater samples. ${ }^{49,54,56,105,108,110,113,115}$

It is not surprising, then, that procrastination and difficulty with time management have also been shown to relate to stimulant misuse among college students. ${ }^{115}$ Further, stimulant misuse among college students has been shown to relate to higher levels of hyperactivity, sensation seeking, depression, internal restlessness, and psychological distress and lower levels of premeditation. ${ }^{44,58,104,114,116}$ ADHD diagnoses and symptoms may also relate to stimulant misuse. Adolescents, college students, and adults diagnosed with ADHD have reported higher levels of prescription stimulant misuse than students without ADHD, and ADHD symptoms have been shown to correlate with nonmedical use of prescription stimulants. ${ }^{57,84,95,117}$ It is important to note, however, that studies suggest that the vast majority of individuals with ADHD do not misuse or divert their stimulant medications. ${ }^{84}$

The studies included in the present review also indicate that in addition to ADHD, diagnoses of conduct disorder and SUD are associated with increased nonmedical prescription stimulant use and diversion in adolescents and adults. ${ }^{84}$ Illicit drug use among adolescent and university students is also associated with misuse of prescription stimulants. ${ }^{52,56,90,91,93,98,101,103,104,107,115,118,119}$

Several studies in the current review assessed student perspectives on prescription stimulant misuse, and findings revealed that students' opinions on the ethical implications of taking illicit prescription stimulant medications to enhance academic outcomes are mixed. For example, Bossaer et $\mathrm{al}^{108}$ reported that health care students were split between considering stimulant misuse to be academically dishonest and proffering unfair academic advantages. Similarly, half of the medical students sampled by Emanuel et al ${ }^{107}$ perceived stimulant misuse to be a problem, but $20 \%$ did not. Students who report engaging in stimulant misuse, however, may feel less conflicted regarding ethical implications. For example, Judson and Langdon ${ }^{48}$ reported that compared with nonillicit users, illicit users demonstrated fewer concerns regarding the safety and ethics of using stimulant medication.

Whether or not students consider their decision to engage in stimulant misuse to be ethical, students misusing stimulants appear to expect positive outcomes. ${ }^{107,116}$ Indeed, students who have reported taking stimulant medications illicitly have endorsed feeling a reduction in fatigue and improvement in cognition and memory after taking prescription stimulants. ${ }^{54}$ The present findings also indicate that students who misuse tend to perceive the benefits as outweighing the risks, despite the fact that little is known about the physiological and cognitive effects of prescription stimulant medications among populations without ADHD. ${ }^{49}$ Two of the reviewed studies suggest that individuals misusing stimulants may be more likely to take short-acting agents than long-acting agents. Wilens et $\mathrm{al}^{84}$ and Bright, ${ }^{97}$ for example, reported that adolescents and adults were more likely to misuse short-acting agents than long-acting agents, suggesting that immediate-release agents have more potential for abuse. Results were mixed regarding the most commonly misused fast-acting stimulant, with Ritalin (MPH) more likely to be misused than Adderall among adults, but nearly $12 \%$ of college students reported misusing Adderall compared with $8.5 \%$ misusing Ritalin. ${ }^{88,115}$

\section{Discussion Effectiveness of ADHD treatment options}

Studies included in this review revealed that the medical use of prescription stimulants is efficacious in reducing ADHD symptoms and may improve cognitive and psychosocial outcomes in individuals diagnosed with ADHD. Specifically, research investigating LDX in comparison with placebo consistently found LDX efficacious across 30,50 , and $70 \mathrm{mg} /$ day. Two studies, however, found that higher doses related to greater improvements in overall functioning. ${ }^{37,62}$ Most notably, the present findings support that LDX is effective for reducing ADHD symptomatology across different ages. ${ }^{37,61,62}$ Among adults with ADHD, LDX was also found to positively affect executive functions, quality of life, and performance productivity. ${ }^{35,64,66}$ Additionally, LDX has been found to be effective in reducing ADHD symptoms with individuals with comorbid depression and SUD. ${ }^{63}$ Although these results are encouraging, it is important to note that most 
studies did report negative side effects from LDX, such as decreased appetite, weight loss, and nasal congestion. More severe side effects, however, including tachycardia, increased blood pressure/hypertension, and anxiety, were reported by $<5 \%$ of the included study samples, and no individuals died while participating in these studies.

Similar to those investigating LDX, studies examining the efficacy of MPH and D-AMP consistently found such treatment options to be associated with fewer ADHD symptoms compared with placebo. These positive effects were found among longacting and short-acting stimulant medications, and one study reported similar effects for both males and females. ${ }^{78}$ Although higher doses generally proved to be more effective at reducing ADHD symptoms, low to moderate doses of stimulants may also be effective at reducing ADHD symptomatology. ${ }^{70,74,76}$ Such treatment options examined in this review were associated with enhanced cognitive performance, executive functioning, and quality of life and fewer emotional symptoms. ${ }^{68,77,81}$ Although MPH and D-AMP have proved to be efficacious in treating ADHD symptomatology, it is important to consider their side effects that are similar to LDX: decreased appetite, weight loss, headache, insomnia, abdominal pain, dizziness, nervousness, emotional lability, and dry mouth. Although rare, more severe side effects of these medications have included psychosis, seizures, and cardiac events such as tachycardia, hypertension, myocardial infarction, and sudden death. ${ }^{120}$

Overall, however, these results are consistent with the child literature indicating that prostimulant and stimulant medications, when used as prescribed, are a safe and efficacious treatment option for improving attention and decreasing hyperactivity and impulsivity symptoms. ${ }^{23,34-38,40-42}$ What remains less clear, however, is whether these medications affect academic and work-related outcomes of adolescents and adults without ADHD. Although one study reported improvements in measured cognition from MPH and another found that students who misuse stimulant medication perceive positive academic effects, ${ }^{54,68}$ none of the studies included in the present review examined changes in quality of work or student grade or productivity after taking stimulant medications. Given that cognitive enhancement-related reasons are considered the primary motivation for college students misusing prescription stimulant medications, future research examining the effects of prescription stimulants on direct measures of academic success (eg, studying and concentration, grade performance, quality of writing, and reading comprehension) is warranted.

An additional area that warrants attention concerns the efficacy of nonstimulant medication for the reduction of ADHD symptoms and any potential effects for cognitive enhancement. The present review was unable to identify any studies examining nonstimulant efficacy among adults and adolescents meeting the required eligibility criteria. Given the lower abuse potential associated with nonstimulant medication, use of these medications among populations more susceptible to diversion and misuse may be prudent. ${ }^{32}$ Such a recommendation, however, is contingent on a demonstration of the efficacy of nonstimulants among adolescent and adult populations most at risk for stimulant abuse. ${ }^{32}$

Finally, although prescription stimulant medication is considered the front line of pharmacotherapy for ADHD treatment in adolescents and adults, these drugs have significant diversion and misuse potential. ${ }^{43}$ In fact, the present review revealed that the medical use of prescription stimulants is associated with increased stimulant misuse among students with ADHD, with one study reporting misuse rates of $62.8 \%$ among participants with a valid prescription. ${ }^{104}$

\section{Stimulant misuse}

Results from the present review indicate that a significant percentage of adolescents and adults are engaging in nonmedical stimulant misuse, which is consistent with previous research examining college students specifically. ${ }^{45}$ Results revealed lifetime prevalence rates of stimulant misuse ranging from $1.7 \%$ to $55 \%$, with reports varying across the population being examined. ${ }^{90,91} \mathrm{~A}$ limitation of this body of literature is the dearth of studies investigating the prevalence of prescription stimulant misuse among college students outside of the US, which impedes cross-cultural comparisons regarding prescription stimulant misuse.

Similar to previous studies examining the nonmedical use of stimulants, the present review revealed that estimates vary according to numerous variables. For example, one trend that has emerged is that as individuals reach higher grade levels, they misuse at greater rates. ${ }^{56,98}$ Although increased exposure to prescription stimulants may be one reason students report higher prevalence rates of stimulants as they increase in age, these findings suggest that prescription stimulants may also be misused more frequently as coursework becomes more challenging and academic success becomes more difficult to obtain. Indeed, as indicated in this review, academic performance has been reported as the primary motive for this behavior. A critical finding, however, is that prescription stimulant misuse has been found to be negatively associated with academic performance. ${ }^{44,90,101}$ For example, Arria et $\mathrm{al}^{121}$ reported that college freshmen who used prescription stimulants nonmedically had poorer study skills (eg, skipped classes more often and spent less time studying and more time socializing) and poorer academic performance (GPA) in high school and college than students who did not endorse stimulant misuse. ${ }^{51}$ 
Despite the negative relationship between academic performance and stimulant misuse, most students who endorse the nonmedical use of stimulants perceive them as effective and helpful for enhancing their academic performance. ${ }^{49}$ For example, Weyandt et a ${ }^{14}$ found that $>20 \%$ of students in their sample agreed or strongly agreed that the occasional nonmedical use of prescription stimulants is harmless. Additionally, stimulant misusers may be less concerned about the safety and ethical implications of stimulant misuse compared with students who do not misuse stimulants. ${ }^{48}$ Findings suggest, however, that general student populations are conflicted about the ethical implications of stimulant misuse.

Although individuals without ADHD have endorsed positive effects from misusing stimulant medication, to date only one study has explored the effects of Adderall on college students without ADHD, and this study, in general, did not find enhancement of cognitive abilities, despite the students' impression that it was improving their performance. ${ }^{122}$ Similar performance-enhancing impressions have been made of MPH, and have led to the popularity of its use among adolescents and college students with and without ADHD. ${ }^{123}$ In addition, the present review suggests that adolescents and adults are more likely to misuse short-acting or immediate-release agents compared with long-acting agents. ${ }^{84,97}$ Consistent with previous studies, the present review suggests that students who are white, affiliated with a fraternity or sorority, engaging in other illicit drugs, and male, are more likely to misuse prescription stimulants. . $7,49,56,57,84,89,92,94,96,101,102,113,118,124^{2}$ Although some of the studies reported no sex differences, recently Weyandt et $\mathrm{l}^{45}$ reported on the effect sizes of sex differences in studies examining stimulant misuse. Cohen's $d$ effects ranged from 0.88 to 5.38 , suggesting that males are misusing at greater rates than females. ${ }^{109,110,125}$

\section{Implications}

Pharmacotherapy is the principal choice of treatment for ADHD among children, adolescents, college students, and adults. ${ }^{28,29}$ Because stimulants are the most frequently prescribed drug for college students with ADHD, and most college students with ADHD take prescription stimulants, more double-blind, placebo-controlled studies examining the effectiveness of these medications in college students are warranted. ${ }^{22}$ It is important to note, however, that there is recent evidence that prostimulants may also be effective at improving symptoms in individuals with ADHD. ${ }^{28}$

The present review provides evidence that college students with ADHD and those with a stimulant prescription are taking part in greater levels of stimulant misuse compared with those without the disorder. ${ }^{103,104}$ Although individuals with ADHD may greatly benefit from stimulant medication, these prescription medications have significant abuse potential when they are not used as prescribed. ${ }^{43}$ All prescription stimulants that are used to treat ADHD are controlled substances; however, abuse liability varies based on the delivery system in which the medication activates. ${ }^{126}$ For example, Svetlov et al ${ }^{123}$ reported that although MPH and AMPH have similar psychopharmacological effects, they do have different neurochemical mechanisms of action. Such differences are essential to consider, as MPH appears to have less rewarding abilities, lowering its chances of dependence, especially when taken as prescribed. A second example includes the requirement of enzymatic hydrolysis for LDX before its therapeutic effects are achieved, which results in a slow increase of D-AMP levels, potentially lowering its use for diversion or misuse. ${ }^{37,127}$ Indeed, recent research has examined the effects of LDX in a group of stimulant abusers who did not have ADHD, and found that intravenous doses of LDX had greater abuse-related disliking compared with placebo. ${ }^{127}$ Specifically, Jasinski and Krishnan ${ }^{127}$ administered $100 \mathrm{mg}$ of LDX and $40 \mathrm{mg}$ of D-AMP to individuals, also reporting that intravenous doses of D-AMP have significantly more abuse-related liking effects compared with placebo. Additionally, because of its chemical properties, LDX cannot be ground or dissolved into a short-acting stimulant, which has been the stimulant of choice for stimulant misusers. Given the demonstrated effects of LDX on improving ADHD symptomology, as well as executive function, and its demonstrated greater abuserelated disliking, LDX may be the ADHD medication of choice for college students with ADHD who are at risk for stimulant misuse. ${ }^{37,127}$ LDX may also be a good choice for prescribers working with the college student population to help prevent stimulant diversion among valid prescription holders and misuse among college students without ADHD. Results of this review also suggest that health care providers should inform their patients of the health and legal risks associated with the misuse of prescription medications, and monitor the use of these medications on a frequent basis. Lastly, health care providers involved in prescribing ADHD-related medications should be thoroughly trained in the proper assessment, diagnosis, and treatment of ADHD to ensure diagnostic accuracy and treatment effectiveness.

In addition to educating prescribers about the rates of misuse and diversion, as well as the variables associated with stimulant misuse, it is critical that prevention and intervention efforts be made amongst health care providers and educators 
at the middle school, high school, and higher education levels. Further efforts should target particularly higher-risk college populations such as fraternities and sororities. Information regarding the potential side effects of stimulant medications taken at varying doses and by different methods (eg, snorting or injecting), in addition to side effects resulting from the ingestion of medication as prescribed, should be made available to students in particular. Students should also be informed of the dangers of coingestion of prescription stimulants with other substances (eg, alcohol and cocaine), and particular emphasis should be placed on maintaining security of their medication (eg, lockboxes). Students who are misusing prescription stimulants without medical guidance are placing themselves at health and psychological risk, in addition to legal consequences for buying, selling, and diverting their medications. ${ }^{120}$

The inclusion of a psychoeducational component that focuses on inaccurate perceptions of safety surrounding nonmedical prescription stimulant use would be beneficial to intervention as well. Students who are at risk for stimulant misuse with academic problems can be provided with various support, such as tutoring and structured environments for studying and work completion. This additional support may encourage a school culture of clear expectations, educational support, and effective study habits, rather than competitiveness. For individuals who have been misusing stimulants or are inclined to misuse, it is imperative to discuss the motivating factors and determine any possibly undiscovered psychological, social, and/or emotional problems related to misuse or the desire to misuse. By pinpointing and addressing the core cause of stimulant use, students can be provided with the resources that will directly provide them with benefits and alternative methods to meet their specific needs. Thus, students should be educated about the potential side effects and risks associated with prescription stimulant misuse, as well as encouraged to access campus resources for academic and psychological support..$^{45,47}$

\section{Conclusion}

Results from the present review support that both stimulant and prostimulant medications (including LDX, MPH, AMPH, and MAS), when used as prescribed, are safe and effective options for reducing ADHD symptoms in adolescents and adults with ADHD. Preliminary studies also suggest that prescription stimulants may improve psychosocial outcomes (eg, quality of life, self-concept, and obsessivecompulsive symptoms) for those with ADHD. Research explicitly examining effects of prescription stimulants on academic and cognitive functioning in students without
ADHD is sorely limited, yet the current review revealed that alarmingly high percentages of adolescents and adults are engaging in nonmedical prescription stimulant use primarily for cognitive enhancement. Results of the present review also revealed a higher rate of prescription stimulant misuse among individuals with ADHD compared with individuals without the disorder, and that short-acting agents are more likely to be misused than long-acting agents. These findings emphasize the need for additional research concerning the misuse of prescription stimulants and have direct implications for prevention and intervention efforts to reduce prescription stimulant misuse among adolescents and young adults.

\section{Acknowledgment}

Research reported in this publication was supported by the National Center for Research Resources of the National Institutes of Health under Award Number G20RR030883. The content is solely the responsibility of the authors and does not necessarily represent the official views of the National Institutes of Health.

\section{Disclosure}

The authors report no conflicts of interest in this work.

\section{References}

1. American Psychiatric Association. Diagnostic and Statistical Manual of Mental Health Disorders: DSM-5. 5th ed. Washington, DC: American Psychiatric Publishing; 2013.

2. Barkley RA, Murphy KR, Fischer, M. ADHD in Adults: What the Science Says. New York, NY: Guilford; 2008.

3. Resnick RJ. Attention deficit hyperactivity disorder in teens and adults: they don't all outgrow it. J Clin Psychol. 2005;61(5):529-533.

4. Kessler RC, Adler L, Barkley R, et al. The prevalence and correlates of adult ADHD in the United States: results from the National Comorbidity Survey replication. Am J Psychiatry. 2006;163(4): 716-723.

5. Faraone SV, Biederman J, Lehman BK, et al. Intellectual performance and school failure in children with attention deficit hyperactivity disorder and in their siblings. J Abnorm Child Psychol. 1993;102(4): 616-623.

6. Barkley RA. Attention-Deficit Hyperactivity Disorder: A Handbook for Diagnosis and Treatment. 3rd ed. New York: Guilford; 2006.

7. Danforth JS, Connor DF, Doerfler LA. The development of comorbid conduct problems in children with ADHD: an example of an integrative developmental psychopathology perspective. JAtten Disord. Epub January 10, 2014.

8. Barkley RA, Fischer M, Edelbrock CS, Smallish L. The adolescent outcome of hyperactive children diagnosed by research criteria: an 8-year prospective follow-up study. $\mathrm{J}$ Am Acad Child Adolesc Psychiatry. 1990;29(4):546-557.

9. Molina BS, Hinshaw SP, Swanson JM, et al; for the MTA Cooperative Group. The MTA at 8 years: prospective follow-up of children treated for combined-type ADHD in a multisite study. JAm Acad Child Adolesc Psychiatry. 2009;48(5):484-500.

10. Biederman J, Mick E, Faraone SV. Age-dependent decline of symptoms of attention deficit hyperactivity disorder: impact of remission definition and symptom type. Am J Psychiatry. 2000;157(5):816-818. 
11. Weyandt LL, Iwaszuk W, Fulton K, et al. The Internal Restlessness Scale: performance of college students with and without ADHD. J Learn Disabil. 2003;36(4):382-389.

12. Sibley MH, Kuriyan AB, Evans SW, Waxmonsky JG, Smith BH. Pharmacological and psychosocial treatments for adolescents with ADHD: an updated systematic review of the literature. Clin Psychol Rev. 2014;34(3):218-232.

13. Weyandt LL, DuPaul GJ. College Students with ADHD: Current Status and Future Directions. New York: Springer; 2013.

14. Americans With Disabilities Act 1991, Pub L No 101-336, 26 July 1990, 104 Stat 328 (1991). Available from http://www.ada.gov/pubs/ adastatute 08.htm. Accessed July 25, 2014.

15. Wolf LE, Simkowitz P, Carlson H. College students with attention-deficit/ hyperactivity disorder. Curr Psychiatry Rep. 2009;11(5):415-421.

16. Weyandt LL, Linterman I, Rice JA. Reported prevalence of attention difficulties in a general sample of college students. $J$ Psychopathol Behav Assess. 1995;17(3):293-304.

17. Garnier-Dykstra LM, Pinchevsky GM, Caldeira KM, Vincent KB, Arria AM. Self-reported adult attention-deficit/hyperactivity disorder symptoms among college students. J Amer Coll Health Assoc. 2010;59(2):133-136.

18. Heiligenstein E, Conyers LM, Berns AR, Miller MA. Preliminary normative data on DSM-IV attention deficit hyperactivity disorder in college students. J Amer Coll Health Assoc. 1998;46(4):185-188.

19. McKee T. Comparison of a norm-based versus criterion-based approach to measuring ADHD symptomatology in college students. $J$ Attent Disord. 2008;11(6):677-688.

20. Norwalk K, Norvilitis JM, MacLean MG. ADHD symptomatology and its relationship to factors associated with college adjustment. J Attent Disord. 2009;13(3):251-258.

21. Shaw-Zirt B, Popali-Lehane L, Chaplin W, Bergman A. Adjustment, social skills, and self-esteem in college students with symptoms of ADHD. J Attent Disord. 2005;8(3):109-120.

22. Advokat CD, Lane SM, Luo C. College students with and without ADHD: comparison of self-report of medication usage, study habits, and academic achievement. J Attent Disord. 2011;15(8):656-666.

23. Heiligenstein E, Guenther G, Levy A, Savino F, Fulwiler J. Psychological and academic functioning in college students with attention deficit hyperactivity disorder. Coll Health. 1999;47(4):181-185.

24. Reaser A, Prevatt F, Petscher Y, Proctor B. The learning and study strategies of college students with ADHD. Psychol Sch. 2007;44(6): $627-638$.

25. Weyandt LL, Rice JA, Linterman I, Mitzlaff L, Emert E. Neuropsychological performance of a sample of adults with ADHD, developmental reading disorder, and controls. Dev Neuropsychol. 1998;14(4):643-656.

26. Canu WH, Carlson CL. Rejection sensitivity and social outcomes of young adult men with ADHD. J Atten Disord. 2007;10(3):261-275.

27. Rabiner DL, Anastopoulos AD, Costello EJ, Hoyle RH, McCabe SE, Swartzwelder HS. Adjustment to college in students with ADHD. J Atten Disord. 2008;11(6):689-699.

28. Baverstock AC, Finlay F. Who manages the care of students with attention deficit hyperactivity disorder (ADHD) in higher education? Child Care Health Dev. 2003;29(3):163-166.

29. Spencer TJ, Biederman J, Wilens T. Pharmacotherapy of ADHD with antidepressants. In: Barkley R, editors. Attention-Deficit Hyperactivity Disorder: A Handbook for Diagnosis and Treatment. 2nd ed. New York: Guilford Press; 1998:552-563.

30. Bushe CJ, Savill NC. Systematic review of atomoxetine data in childhood and adolescent attention-deficit hyperactivity disorder 2009-2011: focus on clinical efficacy and safety. J Psychopharmacol. (Oxford, England). 2014;28(3):204-211.

31. Faraone SV, Biederman J, Spencer T, et al. Efficacy of atomoxetine in adult attention-deficit/hyperactivity disorder: a drug-placebo response curve analysis. Behav Brain Funct. 2005;1:16.

32. Kooij SJ, Bejerot S, Blackwell A, et al. European consensus statement on diagnosis and treatment of adult ADHD: the European Network Adult ADHD. BMC Psychiatry. 2010;10:67.
33. Ni HC, Shang CY, Gau SS, Lin YJ, Huang HC, Yang LK. A head-to-head randomized clinical trial of methylphenidate and atomoxetine treatment for executive function in adults with attention-deficit hyperactivity disorder. Int J Neuropsychopharmacol. 2013;16(9):1959-1973.

34. Adler LA, Spencer T, McGough JJ, Jiang H, Muniz R. Long-term effectiveness and safety of dexmethylphenidate extended release capsules in adult ADHD. J Atten Disord. 2009;12(5):449-459.

35. Adler LA, Dirks B, Deas PF, et al. Lisdexamfetamine dimesylate in adults with attention-deficit/hyperactivity disorder who report clinically significant impairment in executive function: results from a randomized, doubleblind, placebo-controlled study. J Clin Psychiatry. 2013;74(7):694-702.

36. Advokat $\mathrm{C}$. What are the cognitive effects of stimulant medications? Emphasis on adults with attention-deficit/hyperactivity disorder (ADHD). Neurosci Biobehav Rev. 2010;34(8):1256-1266.

37. DuPaul GJ, Weyandt LL, Rossi, JS, et al. Double-blind, placebocontrolled, crossover study of the efficacy and safety of lisdexamfetamine dimesylate in college students with ADHD. J Atten Disord. 2012;16(3):202-220.

38. DuPaul GJ, Weyandt LL, O’Dell, SM, Varejao M. College students with ADHD: current status and future directions. J Atten Disord. 2009;13(3):234-250.

39. Heiligenstein E, Guenther G, Hsu K, Herman K. Depression and academic impairment in college students. J Amer Coll Health Assoc. 1996;45(2):59-64.

40. Huss M, Ginsberg Y, Tvedten T, et al. Methylphenidate hydrochloride modified release improved inattention and hyperactivity/impulsivity scores in adult ADHD patients. Eur Neuropsychopharmacol. 2013;23(2):604-605.

41. Staufer WB, Greydanus DE. Attention-deficit/hyperactivity disorder psychopharmacology for college students. Pediatr Clin North Amer. 2005;52(1):71-84.

42. Weyandt LL, DuPaul GJ. ADHD in college students: a review of the literature. J Atten Disord. 2006;10(1):9-19.

43. Kollins SH. Abuse liability of medications used to treat attention-deficit/ hyperactivity disorder (ADHD). Amer J Addict. 2007;16(1):35-44.

44. Weyandt LL, Janusis G, Wilson KG, et al. Nonmedical prescription stimulant use among a sample of college students: relationship with psychological variables. J Atten Disord. 2009;13(3):284-296.

45. Weyandt LL, Marraccini ME, Gudmundsdottir BG, et al. Misuse of prescription stimulants among college students: a review of the literature and implications for morphological and cognitive effects on brain functioning. Exp Clin Psychopharmacol. 2013;21(5):385-407.

46. Babcock Q, Byrne T. Student perceptions of methylphenidate abuse at a public liberal arts college. J Amer Coll Health Assoc. 2009;49(3): $143-145$.

47. Dussault C, Weyandt LL. An examination of prescription stimulant misuse and psychological variables among sorority and fraternity college populations. J Atten Disord. 2013;17(2):87-97.

48. Judson R, Langdon SW. Illicit use of prescription stimulants among college students: prescription status, motives, theory of planned behaviour, knowledge and self-diagnostic tendencies. Health Psychol Behav Med. 2009;14(1):97-104.

49. Rabiner DL, Anastopoulos AD, Costello EJ, Hoyle RH, McCabe SE, Swartzwelder HS. Motives and perceived consequences of nonmedical ADHD medication use by college students: are students treating themselves for attention problems? J Atten Disord. 2009;13(3):259-270.

50. Verdi G, Weyandt LL, Zavras BM. Non-medical prescription stimulant use in graduate students: relationship with academic self-efficacy and psychological variables. J Atten Disord. Epub April 22, 2014.

51. McCabe SE, Knight JR, Teter CJ, Wechsler H. Non-medical use of prescription stimulants among US college students: prevalence and correlates from a national survey. Br J Addict. 2005;99(1):96-106.

52. Sharp JT, Rosén, LA. Recreational stimulant use among college students. J Subst Use. 2007;12(2):71-82.

53. Dupont RL, Coleman JJ, Bucher RH, Wilford BB. Characteristics and motives of college students who engage in nonmedical use of methylphenidate. Am J Addict. 2008;17(3):167-171. 
54. DeSantis AD, Webb EM, Noar SM. Illicit use of prescription ADHD medications on a college campus: a multimethodological approach. J Am Coll Health Assoc. 2008;57(3):315-324.

55. US Food and Drug Administration. FDA Directs ADHD Drug Manufacturers to Notify Patients About Cardiovascular Adverse Events and Psychiatric Adverse Events; 2007. Available from: http://www.fda. gov/NewsEvents/Newsroom/PressAnnouncements/2007/ucm108849. htm. Accessed June 25, 2014.

56. Garnier-Dykstra LM, Caldeira KM, Vincent KB, O'Grady KE, Arria AM. Nonmedical use of prescription stimulants during college: four-year trends in exposure opportunity, use, motives, and sources. $J$ Am Coll Health Assoc. 2012;60(3):226-234.

57. Arria AM, Garnier-Dykstra LM, Caldeira KM, Vincent KB, O'Grady KE, Wish ED. Persistent nonmedical use of prescription stimulants among college students: possible association with ADHD symptoms. J Atten Disord. 2011;15(5):347-356.

58. Teter CJ, Falone AE, Cranford JA, Boyd CJ, McCabe SE. Non-medical use of prescription stimulants and depressed mood among college students: frequency and routes of administration. $J$ Subst Abuse Treat 2010;38(3):292-298

59. Okoli C, Schabram K. A guide to conducting a systematic literature review of information systems research. Sprouts: Working Papers on Information Systems. 2010;10(26):1-49.

60. Cohen J. A power primer. Psychol Bull. 1992;112:155-159.

61. Adler LA, Goodman DW, Kollins SH, et al. Double-blind, placebo-controlled study of the efficacy and safety of lisdexamfetamine dimesylate in adults with attention-deficit/hyperactivity disorder. $J$ Clin Psychiatry. 2008;69(9):1364-1373.

62. Faraone SV, Spencer TJ, Kollins SH, Glatt SJ, Goodman D. Dose response effects of lisdexamfetamine dimesylate treatment in adults with ADHD: an exploratory study. J Atten Disord. 2012;16(2):118-127.

63. Kollins SH, Youcha S, Lasser R, Thase ME. Lisdexamfetamine dimesylate for the treatment of attention deficit hyperactivity disorder in adults with a history of depression or history of substance use disorder Innov Clin Neurosci. 2011;8(2):28-32.

64. Wigal SB, Wigal T, Schuck S, et al. Academic, behavioral, and cognitive effects of OROS methylphenidate on older children with attention deficit/hyperactivity disorder. $J$ Child Adolesc Psychopharmacol. 2011;21(2):121-131

65. Findling RL, Childress AC, Cutler AJ, et al. Efficacy and safety of lisdexamfetamine dimesylate in adolescents with attentiondeficit/hyperactivity disorder. $J$ Am Acad Child Adolesc Psychiatry. 2011;50(4):395-405.

66. Brams M, Giblin J, Gasior M, Gao J, Wigal T. Effects of open-label lisdexamfetamine dimesylate on self-reported quality of life in adults with ADHD. Postgrad Med. 2011;123(3):99-108.

67. Brams M, Weisler R, Findling RL, et al. Maintenance of efficacy of lisdexamfetamine dimesylate in adults with attention-deficit/hyperactivity disorder: randomized withdrawal design. J Clin Psychiatry. 2012;73(7):977-983.

68. Agay N, Yechiam E, Carmel Z, Levkovitz Y. Non-specific effects of methylphenidate (Ritalin) on cognitive ability and decisionmaking of ADHD and healthy adults. Psychopharmacology (Berl) 2010;210(4):511-519.

69. Jain U, Hechtman L, Weiss M, et al. Efficacy of a novel biphasic controlled-release methylphenidate formula in adults with attention-deficit/hyperactivity disorder: results of a double-blind, placebo-controlled crossover study. J Clin Psychiatry. 2007;68(2): 268-277.

70. Medori R, Ramos-Quiroga JA, Casas M, et al. A randomized, placebocontrolled trial of three fixed dosages of prolonged-release OROS methylphenidate in adults with attention-deficit/hyperactivity disorder. Biol Psychiatry. 2008;63(10):981-989.

71. Retz W, Rösler M, Ose C, et al. Multiscale assessment of treatment efficacy in adults with ADHD: a randomized placebo-controlled, multi-centre study with extended-release methylphenidate. World $J$ Biol Psychiatry. 2012;13(1):48-59.
72. Spencer T, Biederman J, Wilens T, et al. A large, double-blind, randomized clinical trial of methylphenidate in the treatment of adults with attention-deficit/hyperactivity disorder. Biol Psychiatry. 2005;57(5):456-463.

73. Spencer T, Wilens T, Biederman J, Weisler R, Read S, Pratt R. Efficacy and safety of mixed amphetamine salts extended release (Adderall XR) in the management of attention-deficit/hyperactivity disorder in adolescent patients: a 4-week, randomized, double-blind, placebocontrolled, parallel-group study. Clin Ther. 2006;28(2):266-279.

74. Spencer TJ, Adler LA, McGough JJ, Muniz R, Jiang H, Pestreich L. Efficacy and safety of dexmethylphenidate extended-release capsules in adults with attention-deficit/hyperactivity disorder. Biol Psychiatry. 2007;61(12):1380-1387.

75. Stein MA, Waldman ID, Charney E, et al. Dose effects and comparative effectiveness of extended release dexmethylphenidate and mixed amphetamine salts. J Child and Adolesc Psychopharmacol. 2011;21(6):581-588.

76. Rösler M, Fischer R, Ammer R, Ose C, Retz W. A randomized, placebo-controlled, 24-week, study of low-dose extended-release methylphenidate in adults with attention deficit/hyperactivity disorder. Eur Arch Psychiatry Clin Neurosci. 2009;259(2):120-129.

77. Rösler M, Retz W, Fischer R, et al. Twenty-four-week treatment with extended release methylphenidate improves emotional symptoms in adult ADHD. World J Biol Psychiatry. 2010;11(5):709-718.

78. Mikami AY, Cox DJ, Davis MT, Wilson HK, Merkel RL, Burket R. Sex differences in effectiveness of extended-release stimulant medication among adolescents with attention-deficit/hyperactivity disorder. J Clin Psychol Med Settings. 2009;16(3):233-242.

79. Bouffard R, Hechtman L, Minde K, Iaboni-Kassab F. The efficacy of 2 different dosages of methylphenidate in treating adults with attention-deficit hyperactivity disorder. Can J Psychiatry. 2003;48(8):546-554.

80. Kooij JJ, Burger H, Boonstra AM, Van der Linden PD, Kalma LE, Buitelaar JK. Efficacy and safety of methylphenidate in 45 adults with attention-deficit/hyperactivity disorder: a randomized placebo-controlled double-blind cross-over trial. Psychol Med. 2004;34(6):973-982.

81. Spencer TJ, Adler LA, Weisler RH, Youcha, SH. Triple-bead mixed amphetamine salts (SPD465), a novel, enhanced extended-release amphetamine formulation for the treatment of adults with ADHD: a randomized, double-blind, multicenter, placebo-controlled study. J Clin Psychiatry. 2008;69(9):1437-1448.

82. Weisler RH, Biederman J, Spencer TJ, et al. Mixed amphetamine salts extended-release in the treatment of adult ADHD: a randomized, controlled trial. CNS Spectr. 2006;11(8):625-639.

83. Biederman J, Mick E, Spencer T, et al. An open-label trial of OROS methylphenidate in adults with late-onset ADHD. CNS Spectr. 2006;11(5):390-396.

84. Wilens T, Kratochvil C, Newcorn J, Gao H. Do children and adolescents with ADHD respond differently to atomoxetine? J Am Acad Child and Adolesc Psychiatry. 2006;45(2):149-157.

85. Wilson HK, Cox DJ, Merkel RL, Moore M, Coghill D. Effect of extended release stimulant-based medications on neuropsychological functioning among adolescents with attention-deficit/hyperactivity disorder. Arch Clin Neuropsychol. 2006;21:797-807.

86. Cooper WO, Habel LA, Sox CM, et al. ADHD drugs and serious cardiovascular events in children and young adults. $N$ Engl $J$ Med. 2011;365(20):1896-1904.

87. Novak SP, Kroutil LA, Williams RL, Van Brunt DL. The nonmedical use of prescription ADHD medications: results from a national Internet panel. Subst Abuse Treat Prev Policy. 2007;2:32.

88. Pilkinton M, Cannatella A. Nonmedical use of prescription stimulants: age, race, gender, and educational attainment patterns. J Hum Behav Soc Environ. 2012;22(4):409-420.

89. Darredeau C, Barrett SP, Jardin B, Pihl RO. Patterns and predictors of medication compliance, diversion, and misuse in adult prescribed methylphenidate users. Hum Psychopharmacol. 2007;22(8): 529-536. 
90. DeSantis A, Noar SM, Webb EM. Nonmedical ADHD stimulant use in fraternities. J Stud Alcohol Drugs. 2009;70(6):952-954.

91. Herman-Stahl MA, Krebs CP, Kroutil LA, Heller DC. Risk and protective factors for nonmedical use of prescription stimulants and methamphetamine among adolescents. J Adolesc Health. 2006;39(3): 374-380.

92. McCabe S, Teter CJ, Boyd CJ. The use, misuse and diversion of prescription stimulants among middle and high school students. Subst Use Misuse. 2004;39(7):1095-1116.

93. Sweeney CT, Sembower MA, Ertischek MD, Shiffman S, Schnoll SH. Nonmedical use of prescription ADHD stimulants and preexisting patterns of drug abuse. J Addict Dis. 2013;32(1):1-10

94. Veliz P, Boyd C, McCabe SE. Adolescent athletic participation and nonmedical Adderall use: an exploratory analysis of a performanceenhancing drug. J Stud Alcohol Drugs. 2013;74(5):714-719.

95. Gordon S, Tulak F, Troncale J. Prevalence and characteristics of adolescent patients with co-occurring ADHD and substance dependence. J Addict Dis. 2004;23(4):31-40.

96. Williams RJ, Goodale LA, Shay-Fiddler MA, Gloster SP, Chang SY. Methylphenidate and dextroamphetamine abuse in substance-abusing adolescents. Am J Addict. 2004;13(4):381-389.

97. Bright GM. Abuse of medications employed for the treatment of ADHD: results from a large-scale community survey. Medscape $J$ Med. 2008;10:111.

98. McCabe SE, West B. Medical and nonmedical use of prescription stimulants: results from a national multicohort study. J Am Acad Child Adolesc Psychiatry. 2013;52(12):1272-1280.

99. Franke AG, Bonertz, CC, Christmann MM, et al. Non-medical use of prescription stimulants and illicit use of stimulants for cognitive enhancement in pupils and students in Germany. Pharmacopsychiatry, 2011;44(2):60-66.

100. Jeffers A, Benotsch EG, Koester S. Misuse of prescription stimulants for weight loss, psychosocial variables, and eating disordered behaviors. Appetite. 2013;65:8-13.

101. McCabe SE, Teter CJ, Boyd CJ. Medical use, illicit use and diversion of prescription stimulant medication. $J$ Psychoactive Drugs. 2006;38(1):43-56.

102. McCabe SE, Teter CJ. Drug use related problems among nonmedical users of prescription stimulants: a web-based survey of college students from a Midwestern university. Drug Alcohol Depend. 2007;91(1):69-76.

103. Advokat CD, Guidry D, Martino L. Licit and illicit use of medications for attention-deficit hyperactivity disorder in undergraduate college students. J Am Coll Health Assoc. 2008;56(6):601-606.

104. Jardin B, Looby A, Earleywine M. Characteristics of college students with attention-deficit hyperactivity disorder symptoms who misuse their medications. J Am Coll Health Assoc. 2011;59(5):373-377.

105. Habibzadeh A, Alizadeh M, Malek A, Maghbooli L, Shoja MM, Ghabil K. Illicit methylphenidate use among Iranian medical students: prevalence and knowledge. Drug Des Devel Ther. 2011;5: 71-76.

106. Tuttle JP, Scheurich NE, Ranseen J. Prevalence of ADHD diagnosis and nonmedical prescription stimulant use in medical students. Acad Psychiatry. 2010;34(3):220-223.

107. Emanuel RM, Frellsen SL, Kashima KJ, Sanguino SM, Sierles FS, Lazarus CJ. Cognitive enhancement drug use among future physicians: findings from a multi-institutional census of medical students. $J$ Gen Intern Med. 2013;28(8):1028-1034.

108. Bossaer JB, Gray JA, Miller SE, Enck G, Gaddipati VC, Enck RE. The use and misuse of prescription stimulants as "cognitive enhancers" by students at one academic health sciences center. Acad Med. 2013;88(7):967-971.

109. McNiel AD, Muzzin KB, DeWald JP, et al. The nonmedical use of prescription stimulants among dental and dental hygiene students. J Dent Educ. 2011;75:365-376.

110. White BP, Becker-Blease KA, Grace-Bishop K. Stimulant medication use, misuse, and abuse in an undergraduate and graduate student sample. J Am Coll Health Assoc. 2006;54(5):261-268.
111. Lensing MB, Zeiner P, Sandvik L, Opjordsmoen S. Adults with ADHD: use and misuse of stimulant medication as reported by patients and their primary care physicians. Atten Defic Hyperact Disord. 2013;5(4):369-376.

112. McCabe SE, Teter CJ, Boyd CJ. Medical use, illicit use, and diversion of abusable prescription drugs. $J$ Am Coll Health Assoc. 2006;54(5):269-278.

113. Teter CJ, McCabe S, Cranford JA, Boyd CJ, Guthrie SK. Prevalence and motives for illicit use of prescription stimulants in an undergraduate student sample. J Am Coll Health Assoc. 2005;53(6):253-262.

114. Herman-Stahl M, Krebs CP, Kroutil LA, Heller DC. Risk and protective factors for methamphetamine use and nonmedical use of prescription stimulants among young adults aged 18 to 25 . Addict Behav. 2007;32(5):1003-1015.

115. Moore D, Burgard D, Larson R, Ferm M. Psychostimulant use among college students during periods of high and low stress: an interdisciplinary approach utilizing both self-report and unobtrusive chemical sample data. Addict Behav. 2014;39(5):987-993.

116. Lookatch SJ, Dunne EM, Katz EC. Predictors of nonmedical use of prescription stimulants. J Psychoactive Drugs. 2012;44(1):86-91.

117. Janusis GM, Weyandt LL. An exploratory study of substance use and misuse among college students with and without ADHD and other disabilities. J Attent Disord. 2010;14(3):205-215.

118. Barrett S, Darredeau C, Bordy LE, Pihl RO. Characteristics of methylphenidate misuse in a university student sample. Can $J$ Psychiatry. 2005;50(8):457-461.

119. Sepulveda DR, Thomas LM, McCabe SE, Cranford JA, Boyd CJ, Teter CJ. Misuse of prescribed stimulant medication for ADHD and associated patterns of substance use: preliminary analysis among college students. J Pharm Pract. 2011;24(6):551-560.

120. Westover AN, Halm EA. Do prescription stimulants increase the risk of adverse cardiovascular events? A systematic review. BMC Cardiovasc Disord. 2012;12:41.

121. Arria AM, O'Grady KE, Caldeira KM, Vincent KB, Wish ED. Nonmedical use of prescription stimulants and analgesics: associations with social and academic behaviors among college students. J Drug Issues. 2008;38(4):1045-1060.

122. Ilieva I, Boland J, Farah MJ. Objective and subjective cognitive enhancing effects of mixed amphetamine salts in healthy people. Neuropharmacology. 2013;64:496-505.

123. Svetlov SI, Kobeissy FH, Gold MH. Performance enhancing, non-prescription use of Ritalin: a comparison with amphetamines and cocaine. J Addict Dis. 2007;26(4):1-6.

124. Teter CJ, McCabe SE, LaGrange K, Cranford JA, Boyd CJ. Illicit use of specific prescription stimulants among college students: prevalence, motives, and routes of administration. Pharmacotherapy. 2006;26(10): 1501-1510.

125. Lord S, Downs G, Furtaw P, et al. Nonmedical use of prescription opioids and stimulants among student pharmacists. JAm Pharm Assoc. 2009;49(4):519-528.

126. Mansbach RS, Moore RA. Formulation considerations for the development of medications with abuse potential. Drug Alcohol Depend. 2006;83(1):15-22.

127. Jasinski DR, Krishnan S. Abuse liability and safety of oral lisdexamfetamine dimesylate in individuals with a history of stimulant abuse. J Psychopharmacol. 2009;23:419-427.

128. Hartung CM, Canu WH, Cleveland CS, et al. Stimulant medication use in college students: comparison of appropriate users, misusers, and nonusers. Psychol Addict Behav. 2013;27(3):832-840.

129. Kroutil LA, Van Brunt DL, Herman-Stahl MA, Heller DC, Bray BM, Penne MA. Nonmedical use of prescription stimulants in the United States. Drug Alcohol Depend. 2006;84:135-143.

130. Clegg-Kraynok MM, McBean MM, Montgomery-Downs HE. Sleep quality and characteristics of college students who use prescription psychostimulants nonmedically. Sleep Med. 2011;12:598-602.

131. Winhusen TM, Lewis DF, Riggs PD, et al. Subjective effects, misuse, and adverse effects of osmotic-release methylphenidate treatment in adolescent substance abusers with attention-deficit/hyperactivity disorder. J Child Adolesc Psychopharmacol. 2011;21:455-463. 


\section{Publish your work in this journal}

Psychology Research and Behavior Management is an international, peerreviewed, open access journal focusing on the science of psychology and its application in behavior management to develop improved outcomes in the clinical, educational, sports and business arenas. Specific topics covered include: Neuroscience, memory \& decision making; Behavior modification \& management; Clinical applications; Business \& sports performance management; Social and developmental studies; Animal studies. The manuscript management system is completely online and includes a quick and fair peer-review system. Visit http://www.dovepress. com/testimonials.php to read real quotes from published authors.

Submit your manuscript here: http://www.dovepress.com/psychology-research-and-behavior-management-journal 